\title{
Teori Medan Klasik
}

Muhammad Gaffar A.A., Byon N. Jayawiguna

Abstract. Teori Medan Klasik adalah bentuk perhitungan fenomena interaksi fisika melalui persamaan medan. Persamaan medan akan memberikan bagaimana materi berinteraksi dengan medan fisis yang dirasakannya. Dimulai dengan mengkonstruksi basis matematis dalam persamaan medan seperti tensor pada dimensi ruangwaktu, kita akan mempelajari proses aljabar yang diperumum terdahulu. Selanjutnya, kita akan mempelajari bahwa teori medan klasik memberikan sudut pandang yang lebih fundamental dalam fisika dibanding formulasi mekanika newton, dimana kita akan dapat secara lebih melihat sifat Lagrangian, simetri, hukum konservasi, dan beberapa transformasi yang dapat dilakukan pada persamaan medan. Teori medan klasik pada dasarnya masih memiliki hukum klasik seperti judulnya, sedangkan formulasi medan yang menggunakan fenomena kuantum didalamnya tidak akan dibahas dalam catatan ini, dan akan dibahas lanjut pada materi persamaan medan kuantum.

\section{Daftar Isi}

1 Relativitas Khusus 1

1.1 Transfromasi Lorentz . . . . . . . . . . . . . . . . . . . . . . . . . 1

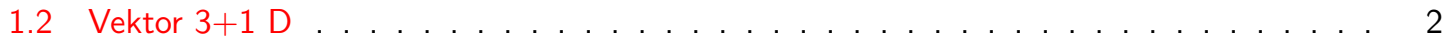

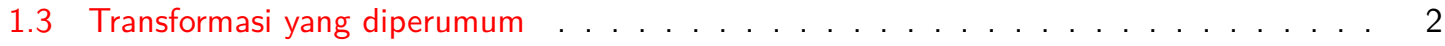

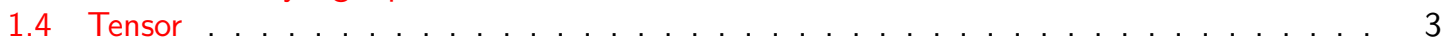

2 Tensor Medan Maxwell 3

2.1 Persamaan Relativistik Maxwell . . . . . . . . . . . . . . . . . . . . . . . . 3

2.2 Tensor Maxwell . . . . . . . . . . . . . . . . . . . . . . . . . . . 5 5

3 Lagrangian $\quad 7$

3.1 Medan Skalar . . . . . . . . . . . . . . . . . . . . . . . . . . . . 7

3.2 Teorema Noether . . . . . . . . . . . . . . . . . . . . . . . . . . . . . . 8

3.3 Lagrangian Medan Maxwell . . . . . . . . . . . . . . . . . . . . . . . . . . . 10

3.4 Invariansi medan skalar kompleks . . . . . . . . . . . . . . . . . . . . . 11

4 Teori Gauge non-Abelian 13

5 Medan Gravitasi 15

5.1 Pendahuluan . . . . . . . . . . . . . . . . . . . . . . . . . . . . . 15

5.2 Simbol Christoffel . . . . . . . . . . . . . . . . . . . . . . . . 16

5.3 Covariant Derivative . . . . . . . . . . . . . . . . . . . . . . . 18

6 Geodesik 19

6.1 Parallel Transport . . . . . . . . . . . . . . . . . . . . . 20 
7 Kelengkungan $\quad 20$

7.1 Properti tensor kelengkungan Riemann . . . . . . . . . . . . . . . . . . . . . . 21

7.2 Tensor Ricci dan Tensor Einstein . . . . . . . . . . . . . . . . . . . . . . . . . . 21

8 Persamaan Medan Einstein 22

8.1 Persamaan medan Einstein dengan Geodesik . . . . . . . . . . . . . . . . . . . 22

8.2 Formulasi Lagrangian: Aksi Hilbert-Einstein . . . . . . . . . . . . . . . . . . . . . . 24

8.3 Solusi Schwarzchild dan Lubang Hitam . . . . . . . . . . . . . . . . . . . . . . 26

$\begin{array}{lr}\text { Appendices } & 28\end{array}$

$\begin{array}{llr}\text { A Lampiran } 1 & 28\end{array}$

B Lampiran $2 \quad 28$

C Lampiran $3 \quad 29$

D Lampiran $4 \quad 30$

E Lampiran $5 \quad 30$

F Lampiran $6 \quad 31$

$\begin{array}{lll}\text { G Lampiran } 7 & 31\end{array}$

$\begin{array}{lll}\text { H } & \text { Lampiran } 8 & 31\end{array}$

I Lampiran $9 \quad 32$

J Lampiran $10 \quad 33$ 


\section{Relativitas Khusus}

Jika terdapat kerangka inersial $\boldsymbol{K}^{\prime}$ yang bergerak relatif dengan kecepatan $v$ terhadap $\boldsymbol{K}$, maka dapat dibuktikkan bahwa

$$
\Delta S=\Delta S^{\prime} \quad \text { dan } \quad \Sigma F^{\prime}=\Sigma F
$$

dimana $\Delta S$ adalah jarak dua titik di kedua kerangka, dan $\Sigma F$ adalah gaya yang bekerja di kedua kerangka. Kedua kuantitas invarian. Sifat invarian ini berlaku jika hanya pada batas fisika newton, dimana kecepatan realtif kerangka $\boldsymbol{K}^{\prime}$ tidak masih jauh dibandingkan kecepatan cahaya. Efek ini akan kita lihat di pembahasan dibawah.

\subsection{Transfromasi Lorentz}

Salah satu hasil pengamatan penting adalah kenyataan bahwa 'Kecepatan Cahaya Berlaku di Semua Kerangka Acuan'. Hasil pengamatan ini memberikan fakta bahwa kita tidak bisa semerta-merta dapat mengkonstruksi transformasi kerangka yang bergerak relatif terhadap kerangka lain dengan bentuk $\boldsymbol{K}^{\prime}=\boldsymbol{K}-\boldsymbol{v} t$. Untuk memenuhi pernyataan ini dalam logika matematis, maka diperlukan paramater tambahan untuk membantu mengkonstruksi matematis yang tepat, yakni transformasi antar kerangka (yang bergerak relatif konstan) dilihat sebagai

$$
x^{\prime}=\gamma(x-v t) \quad \text { atau } \quad x=\gamma\left(x^{\prime}+v t^{\prime}\right)
$$

Dimana $\gamma$ adalah suku tambahan agar pernyataan akan kecepatan cahaya terpenuhi. Untuk mencari nilai $\gamma$, dapat dilakukan proses aljabar, dimana dari (1.2) dapat dibentuk

$$
x=\gamma\left(\gamma(x-v t)+v t^{\prime}\right)=\gamma^{2} x-\gamma^{2} v t+\gamma v t^{\prime}
$$

dan waktu pada kerangka $K^{\prime}$, yakni $t^{\prime}$, dapat dibentuk pula dari (1.3),

$$
t^{\prime}=\gamma t+\frac{x}{\gamma v}\left(1-\gamma^{2}\right)
$$

Selanjutnya, kita implementasikan pernyataan mengenai 'kecepatan cahaya', dimana ini memenuhi

$$
x^{\prime}=c^{\prime} t^{\prime}=c t^{\prime}
$$

Maka dari (1.2) dan (1.4), didapat

$$
\gamma(x-v t)=c\left(\gamma t+\frac{x}{\gamma v}\left(1-\gamma^{2}\right)\right)
$$

dengan mengimplementasikan pernyataan 'kecepatan cahaya' di kerangka satu, yakni dengan subtitusi $x=c t$, maka akan didapat

$$
\gamma=\frac{1}{\sqrt{1-\frac{v^{2}}{c^{2}}}}
$$

dimana $\gamma$ disebut sebagai faktor Loretnz. Subtitusi ini ke persamaan (1.4), maka disimpulkan transformasi yang memenuhi pernyataan 'kecepatan cahaya' adalah

$$
x^{\prime}=\gamma(x-v t) \quad \text { dan } \quad t^{\prime}=\gamma\left(t-\frac{v}{c^{2}} x\right)
$$

transformasi ini disebut sebagai transformasi Lorentz. Sekarang kita buktikkan secara jelas pernyataan 'kecepatan cahaya' berlaku pada transformasi ini. Pertama, jika kerangka $K^{\prime}$ bergerak dengan kecepatan $v$ terhadap kerangka $K$, dan teradapat objek yang bergerak 
dengan kecepatan $u^{\prime}$ pada kerangka $K^{\prime}$, maka pada kerangka $K$ kecepatan objek akan diukur,

$$
u=\frac{d x}{d t}=\frac{d\left(\gamma\left(x^{\prime}+v t^{\prime}\right)\right)}{d\left(\gamma\left(t^{\prime}+\frac{v}{c^{2}} x^{\prime}\right)\right)}=\frac{d x^{\prime}+v d t^{\prime}}{d t^{\prime}\left(1+\frac{v}{c^{2}} \frac{d x^{\prime}}{d t^{\prime}}\right)}=\frac{u^{\prime}+v}{1+\frac{v}{c^{2}} u^{\prime}}
$$

Perhatikan bahwa jika $u^{\prime}=c$, maka didapat juga bahwa $u=c$, maka postulat fisis kecepatan cahaya terbukti.

Transformasi Lorentz mengisyaratkan bahwa interval waktu merupakan kuantitas yang tidak mutlak untuk kedua kerangka, bergantung dengan kecepatan relatif $v$. Salah satu konsekuensi dari ini adalah bahwa elemen jarak menjadi tidak invarian, dimana

$$
d x^{\prime 2}=\gamma^{2}(d x-v d t)^{2}=\gamma^{2}\left(d x^{2}+v^{2} d t^{2}-2 v d x d t\right) \neq d x^{2}
$$

Dibuat kuantitas invarian yang baru untuk kedua kerangka dalam $(3+1)$ dimensi, dimana

$$
d s^{2} \equiv-(c d t)^{2}+d x^{2}+d y^{2}+d z^{2}
$$

Dapat dibuktikkan bahwa definisi (1.10) berlaku invarian untuk kedua kerangka, yakni (misalkan bergerak relatif terhadap sumbu-x $)^{1}$.

\subsection{Vektor 3+1 D}

Vektor komponen $(-c t, x, y, z)=\left(x^{0}, x^{1}, x^{2}, x^{3}\right)$ dibentuk vektor, dan transformasi lorentznya (yang bergerak relatif terhadap sumbu- $x$ ) dengan ${ }^{2}$

$$
x^{\prime \mu}=\left(\begin{array}{c}
x^{0^{\prime}} \\
x^{1^{\prime}} \\
x^{2^{\prime}} \\
x^{3^{\prime}}
\end{array}\right)=\left(\begin{array}{c}
\gamma\left(x^{0}-\frac{v}{c} x^{1}\right) \\
\gamma\left(x^{1}-\frac{v}{c} x^{0}\right) \\
x^{2} \\
x^{3}
\end{array}\right)=\left(\begin{array}{cccc}
\gamma & -\gamma v / c & 0 & 0 \\
-\gamma v / c & \gamma & 0 & 0 \\
0 & 0 & 1 & 0 \\
0 & 0 & 0 & 1
\end{array}\right)\left(\begin{array}{l}
x^{0} \\
x^{1} \\
x^{2} \\
x^{3}
\end{array}\right)=\Lambda_{\nu}^{\mu^{\prime}} x^{\nu}
$$

Titik posisi $x^{\mu}$ dengan index superscript disebut sebagai kontra-varian. Sedangkan terdapat satu jenis lagi, $x_{\mu}$ disebut sebagai kovarian ${ }^{3}$. Perhatikan bahwa, elemen jarak dapat dinyatakan dengan

$$
d s^{2}=d x^{\mu} d x_{\mu}
$$

proses produk antara vektor kontravarian dan kovarian disebut sebagai kontraksi. Kontraksi akan memberikan suatu besaran skalar. Hubungan kedua jenis ini dapat dinyatakan dengan

$$
x_{\mu}=\left(\begin{array}{cccc}
-1 & 0 & 0 & 0 \\
0 & 1 & 0 & 0 \\
0 & 0 & 1 & 0 \\
0 & 0 & 0 & 1
\end{array}\right) x^{\nu}=\eta_{\mu \nu} x^{\nu}
$$

dimana $\eta_{\mu \nu}$ disebut sebagai tensor metrik, atau metrik ${ }^{4}$.

\subsection{Transformasi yang diperumum}

Secara umum transformasi $\boldsymbol{x}^{\prime} \rightarrow \boldsymbol{x}$, dapat dinyatakan sebagai suatu fungsi $\boldsymbol{x}^{\prime}=\boldsymbol{x}^{\prime}(\boldsymbol{x})$. Dengan menggunakan notasi indeks, transformasi dinyatakan dengan

$$
x^{\prime \mu}=x^{\prime \mu}\left(x^{\nu}\right) ; \quad \text { dan } \quad d x^{\prime \mu}=\frac{\partial x^{\prime \mu}}{\partial x^{\nu}} d x^{\nu}=\Lambda_{\nu}^{\mu^{\prime}} d x^{\nu}
$$

derivatif pada domain yang sama, tentu menghasilkan

$$
\frac{\partial x^{\mu}}{\partial x^{\nu}}=\delta_{\nu}^{\mu}
$$

${ }^{1}$ Buktikkan dengan menggunakan transformasi Lorentz.

2 Einstein Summation: jika terdapat dua indeks yang sama, maka secara implisit menandakan sumasih terhadap indeks tersebut.

${ }^{3}$ Vektor kovarian ditulis

$$
x_{\mu}=\left(\begin{array}{l}
x_{0} \\
x_{1} \\
x_{2} \\
x_{3}
\end{array}\right)=\left(\begin{array}{l}
c t \\
x \\
y \\
z
\end{array}\right)
$$

${ }^{4}$ Elemen jarak dapat dinyatakan kembali dengan hubungan ini sebagai $d s^{2}=\eta_{\mu \nu} d x^{\mu} d x_{\nu}$ 
Lebih jauh lagi, kita konstruksi terlebih dahulu vektor kovarian dan kontra-varian dari jarak dua titik

$$
\text { vektor kovarian } \quad V_{\mu}^{\prime}=\frac{\partial x^{\nu}}{\partial x^{\prime \mu}} V_{\nu} \quad \text { vektor kontra-varian } \quad V^{\prime \mu}=\frac{\partial x^{\prime \mu}}{\partial x^{\nu}} V^{\nu}
$$

Jika kedua jenis vektor dikontraksikan, didapat

$$
A^{\prime \mu} B_{\nu}^{\prime}=\frac{\partial x^{\prime \mu}}{\partial x^{\alpha}} \frac{\partial x^{\alpha}}{\partial x^{\prime \nu}} A^{\alpha} B_{\alpha}=\frac{\partial x^{\prime m} u}{\partial x^{\prime \nu}} A^{\alpha} B_{\alpha}=\delta_{\nu^{\prime}}^{\mu^{\prime}} A^{\mu} B_{\alpha} \rightarrow A^{\prime \mu} B_{\mu}^{\prime}=A^{\alpha} B_{\alpha}
$$

Hal ini memberikan konfirmasi bahwa kuantitas skalar (hasil kontraksi) adalah kuantitas yang tidak berubah pada transformasi.

\subsection{Tensor}

Tensor adalah besaran yang bertranformasi secara linear dan homogen. Vektor merupakan tensor yakni tensor rank-1. Sedangkan transformasi tensor pada rank-2 ditulis

$$
T^{\prime \mu \nu}=\frac{\partial x^{\prime \mu}}{\partial x^{\alpha}} \frac{\partial x^{\prime \nu}}{\partial x^{\beta}} T^{\alpha \beta} \quad T_{\mu \nu}^{\prime}=\frac{\partial x_{\alpha}}{\partial x_{\mu}^{\prime}} \frac{\partial x_{\beta}}{\partial x_{\nu}^{\prime}} T_{\alpha \beta} \quad T_{\nu}^{\prime \mu}=\frac{\partial x^{\prime \mu}}{\partial x^{\alpha}} \frac{\partial x_{\beta}}{\partial x_{\nu}^{\prime}} T_{\beta}^{\alpha}
$$

Dengan pola yang sama ini dapat diperumum ke tensor rank-n.

Perhatikan jika terdapat dua indeks yang sama dalam tensor rank-n, maka tensor tersebut menjadi tensor rank-(n-2), yakni

$$
T_{\alpha}^{\prime \alpha \beta}=\frac{\partial x^{\prime \alpha}}{\partial x^{\kappa}} \frac{\partial x^{\prime \beta}}{\partial x^{\lambda}} \frac{\partial x^{\mu}}{\partial x^{\prime} \alpha} T_{\mu}^{\prime \kappa \lambda}=\delta_{\kappa}^{\mu} \frac{\partial x^{\prime \beta}}{\partial x^{\lambda}} T_{\mu}^{\prime \kappa \lambda}=\frac{\partial x^{\prime \beta}}{\partial x^{\lambda}} T_{\mu}^{\prime \mu \lambda}
$$

\section{Tensor Medan Maxwell}

\subsection{Persamaan Relativistik Maxwell}

Pertama-tama, Persamaan Maxwell ditulis

$$
\begin{array}{ll}
\nabla \cdot E=\rho / \epsilon_{0} & \nabla \times E=-\partial B / \partial t \\
\nabla \cdot B=0 & \nabla \times B=\mu_{0} J+\epsilon_{0} \mu_{0} \partial E / \partial t
\end{array}
$$

dikarenakan terdapat hubungan $\nabla \cdot(\nabla \times f)=0$, maka persamaan kedua dapat dituli

$$
B=\nabla \times A
$$

subtitusi ini ke persamaan 3 Maxwell, didapat ${ }^{5}$

$$
E=-\nabla \phi-\frac{\partial A}{\partial t}
$$

Sekarang misalkan terdapat kerangka $\mathcal{S}_{0}, \mathcal{S}, \overline{\mathcal{S}}$, seperti gambar 1 . Jika terdapat kapasitor plat sejajar dengan densitas muatan $\sigma_{0}$ yang posisinya sejajar dengan bidang $\mathrm{x}-\mathrm{z}$ di kerangka $\mathcal{S}_{0}$. Lebar kapasitor $W$ yang terukur oleh kerangka $\mathcal{S}$ adalah

$$
W=\frac{W_{0}}{\gamma_{0}} \quad \text { dengan } \gamma_{0}=\frac{1}{\sqrt{1-v_{0}^{2} / c^{2}}}
$$

dikarenakan relasi $\sigma=q / A$, maka medan listrik tegak lurus terhadap arah gerak $E^{\perp}$ yang diukur dari kerangka $\mathcal{S}$ akibat kontraksi pada lebar kapasitor adalah

${ }^{5}$ Gunakan hubungan

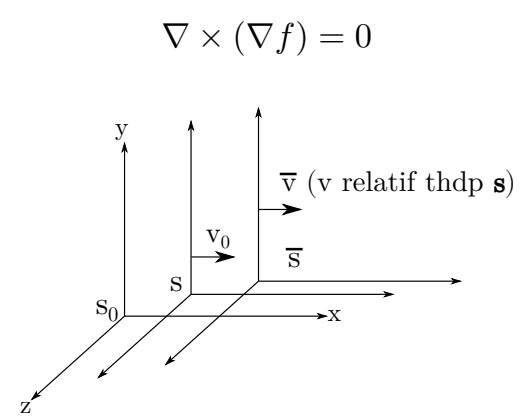

Gambar 1

$$
E_{y}=\frac{\sigma}{\epsilon_{0}}=\gamma_{0} \frac{\sigma_{0}}{\epsilon_{0}}=\gamma_{0} E_{0 y}
$$


Dari pengamat kerangka $\mathcal{S}$, terdapat arus permukaan yang bernilai

$$
\boldsymbol{K}_{ \pm}=\mp \sigma v_{0}
$$

dengan kaidah tangan kanan, kedua arus permukaan ini menghasilkan total medan magnet bernilai

$$
B_{z}=-\mu_{0} \sigma v_{0}
$$

Sekarang, pada kerangka $\overline{\mathcal{S}}$ yang bergerak $v$ relatif terhadap $\mathcal{S}$, maka total kecepatan $\bar{v}$ kerangka $\overline{\mathcal{S}}$ relatif terhadap $\mathcal{S}_{0}$ adalah

$$
\bar{v}=\frac{v+v_{0}}{1+\frac{v v_{0}}{c^{2}}}
$$

dengan

$$
\bar{\gamma}=\frac{1}{\sqrt{1-\bar{v}^{2} / c^{2}}} ; \quad \bar{\sigma}=\bar{\gamma} \sigma_{0}
$$

Jika medan listrik dan magnet yang diukur di kerangka $\overline{\mathcal{S}}$ diekspresikan dengan $\sigma$, didapat

$$
\bar{E}_{y}=\left(\frac{\bar{\gamma}}{\gamma_{0}}\right) \frac{\sigma}{\epsilon_{0}} ; \quad \bar{B}_{z}=-\left(\frac{\bar{\gamma}}{\gamma_{0}}\right) \mu_{0} \sigma \bar{v}
$$

Maka rasio faktor lorentz untuk kedua kerangka, didapat (Lihat Lampiran 1)

$$
\frac{\bar{\gamma}}{\gamma_{0}}=\frac{\sqrt{1-v_{0}^{2} / c^{2}}}{\sqrt{1-\bar{v}^{2} / c^{2}}}=\gamma\left(1+\frac{v v_{0}}{c^{2}}\right)
$$

subtitusi persamaan (2.10) ke (2.9), didapat hubungan

$$
\bar{E}_{y}=\gamma\left(1+\frac{v v_{0}}{c^{2}}\right) \frac{\sigma}{\epsilon_{0}}=\gamma\left(E_{y}-\frac{v}{c^{2} \mu_{0} \epsilon_{0}} B_{z}\right)=\gamma\left(E_{y}-v B_{z}\right)
$$

dan

$$
\bar{B}_{z}=-\gamma\left(1+\frac{v v_{0}}{c^{2}}\right) \mu_{0} \sigma\left(\frac{v+v_{0}}{1+\frac{v v_{0}}{c^{2}}}\right)=\gamma\left(B_{z}-\mu_{0} \sigma v\right)=\gamma\left(B_{z}-\frac{v}{c^{2}} E_{y}\right)
$$

Jika sekarang diposisikan kapasitor sejajar dengan bidang z-y, maka dapat dibuktikkan bahwa $^{6}$

$$
\bar{E}_{x}=E_{x}
$$

Terakhir, diposisikan plat sejajar sebidang dengan bidang $x-y$, maka terjadi kontraksi panjang plat $L$, maka didapatkan seperti halnya pada bidang $x-z$ untuk medan listrik dan medan magnet

$$
E_{z}=\gamma_{0} E_{0 z} \quad \text { dan } \quad B_{y}=\mu_{0} \sigma v_{0}
$$

Perhatikan sekarang nilai medan magnet positif terhadap sumbu koordinat, dengan cara yang sama, namun beda tanda untuk $B$, maka didapatkan

$$
\bar{E}_{z}=\gamma\left(E_{z}+v B_{y}\right) \quad \text { dan } \quad \bar{B}_{y}=\gamma\left(B_{y}+\frac{v}{c^{2}} E_{z}\right)
$$

dengan menulis ulang kembali hasil dari (2.4), (2.12), (2.13), (2.16), dan (2.17), didapat persamaan maxwell secara relativistik.

$$
\begin{aligned}
& \bar{E}_{x}=E_{x}, \bar{B}_{x}=B_{x} \\
& \bar{E}_{y}=\gamma\left(E_{y}-v B_{z}\right), \bar{B}_{y}=\gamma\left(B_{y}+\frac{v}{c^{2}} E_{z}\right) \\
& \bar{E}_{z}=\gamma\left(E_{z}+v B_{y}\right), \bar{B}_{z}=\gamma\left(B_{z}-\frac{v}{c^{2}} E_{y}\right)
\end{aligned}
$$

6 Hanya jarak kedua kapasitor yang mengalami kontraksi, ini tidak memberikan perubahan pada densitas muatan pada plat permukaan kapasitor. 


\subsection{Tensor Maxwell}

Selanjutnya, agar persamaan Maxwell dapat direpresentasikan dalam tensor, pertama kita bentuk vektor potensial untuk $3+1$ dimensi,

$$
A^{\mu}=\left(A^{0}, \boldsymbol{A}\right)=(\phi / c, \boldsymbol{A}) ; \quad A_{\mu}=(-\phi / c, \boldsymbol{A})
$$

Sekarang dibentuk tensor dengan definisi

$$
F^{\mu \nu} \equiv \partial^{\mu} A^{\nu}-\partial^{\nu} A^{\mu}
$$

dan derivatif pada $3+1$ dimensi,

$$
\partial^{\mu}=\left(-\frac{1}{c} \frac{\partial}{\partial t}, \vec{\nabla}\right) ; \quad \partial_{\mu}=\left(\frac{1}{c} \frac{\partial}{\partial t}, \vec{\nabla}\right)
$$

dapat dilihat dengan bahwa $F^{\mu \nu}=-F^{\nu \mu}$.

Pertama, komponen pada baris pertama

$$
F^{0 i}=\partial^{0} A^{i}-\partial^{i} A^{0}=-\frac{1}{c} \frac{\partial A^{i}}{\partial t}-\nabla_{i} \phi=E_{i} / c
$$

Sehingga, komponen pada kolom pertama diberikan oleh hubungan $F_{i 0}=-F_{0 i}$. Untuk komponen selanjutnya $i, j=\{1,2,3\}$,

$$
F^{i j}=\partial^{i} A^{j}-\partial^{j} A^{i}=\epsilon_{i j k} B_{k}
$$

Disimpulkan, masing-masing komponen $F^{\mu \nu}$ adalah

$$
F^{\mu \nu}=\left(\begin{array}{cccc}
0 & E_{x} / c & E_{y} / c & E_{z} / c \\
-E_{x} / c & 0 & B_{z} & -B_{y} \\
-E_{y} / c & -B_{z} & 0 & B_{x} \\
-E_{z} / c & B_{y} & -B_{x} & 0
\end{array}\right)
$$

Selanjutnya, transformasi tensor $F^{\mu \nu}$ diberikan dengan

$$
F^{\prime \mu \nu}=\frac{\partial x^{\prime \mu}}{\partial x^{\alpha}} \frac{\partial x^{\prime \nu}}{\partial x^{\beta}} F^{\alpha \beta}
$$

Dengan dilakukan transformasi lorentz, maka derivatif diatas dapat dibentuk dengan

$$
F^{\prime \mu \nu}=\Lambda_{\alpha}^{\mu^{\prime}} \Lambda_{\beta}^{\nu^{\prime}} F^{\alpha \beta}
$$

Setiap komponen hasil transformasi ini, terbukti sesuai dengan hasil medan Maxwell Relativistik dari pers.(2.14) (Lihat Lampiran 2).

Dari sini, kita dapat mengkonstruksi persamaan medan maxwell dalam bentuk tensor. Mula-mula, dibentuk arus dengan

$$
J^{\mu}=\left(J^{0}, J^{i}\right) \equiv(c \rho, \boldsymbol{J}),
$$

Persamaan $\nabla \cdot \boldsymbol{E}=\rho / \epsilon_{0}$ dapat dibentuk $^{7}$,

${ }^{7}$ Perhatikan dari pers. (39) bahwa

$$
\partial_{i} F^{0 i} c=\frac{1}{\epsilon_{0}} \frac{1}{c} J^{0} \rightarrow \partial_{i} F^{0 i}=\mu_{0} J^{0}
$$

$$
\frac{\nabla \cdot \boldsymbol{E}}{c}=\partial_{i} F^{0 i}
$$

Selanjutnya persamaan keempat, dengan

$$
(\nabla \times \boldsymbol{B})_{i}=\epsilon_{i j k} \partial_{j} B_{k}=-\partial_{j} F^{j i}
$$


dan dari persamaan maxwell keempat pula

$$
\epsilon_{0} \mu_{0} \frac{\partial}{\partial t} E=\epsilon_{0} \mu_{0}\left(c \partial_{0}\right)\left(c F^{0 i}\right)=\partial_{0} F^{0 i}
$$

Maka persamaan $\nabla \times \boldsymbol{B}-\mu_{0} \epsilon_{0} \frac{\partial E}{\partial t}=\mu_{0} J$ dapat dibentuk

$$
-\partial_{j} F^{j i}-\partial_{0} F^{0 i}=\mu_{0} J^{i}
$$

Sehingga hasil (2.24) dan (2.27) dapat digabungkan menjadi

$$
\partial_{\nu} F^{\nu \mu}=-\mu_{0} J^{\mu}
$$

Sekarang untuk persamaan identitas Maxwell $\nabla \cdot B=0$ dan $\nabla \times E=-\partial B / \partial t$. Dapat kita gunakan definisi tensor dual, dimana

$$
\tilde{F}^{\mu \nu}=\frac{1}{2} \epsilon^{\mu \nu \alpha \beta} F^{\alpha \beta}
$$

Dari hal tersebut akan didapat komponennya bernilai (Lihat Lampiran 3),

$$
\tilde{F}^{\mu \nu}=\left(\begin{array}{cccc}
0 & B_{x} & B_{y} & B_{z} \\
-B_{x} & 0 & -E_{z} / c & E_{y} / c \\
-B_{y} & E_{z} / c & 0 & -E_{x} / c \\
-B_{z} & -E_{y} / c & E_{x} / c & 0
\end{array}\right)
$$

Maka untuk $\nabla \cdot B=0$ didapat

$$
\partial_{i} \tilde{F}^{0 i}=-\partial_{i} \tilde{F}^{i 0}=0
$$

dan untuk $\nabla \times E=-\partial B / \partial t$ didapat

$$
-\frac{\partial B}{\partial t}=-c \partial_{0} \tilde{F}^{0 i}
$$

sedangkan $\nabla \times E$ dapat dibentuk sama seperti (2.25), dimana

$$
(\nabla \times \boldsymbol{E})_{i}=c \partial_{j} \tilde{F}^{j i}
$$

Maka

$$
\nabla \times E+\partial B / \partial t=c \partial_{j} \tilde{F}^{j i}+c \partial_{0} \tilde{F}^{0 i}=0
$$

Sehingga

$$
\partial_{\mu} \tilde{F}^{\mu \nu}=0
$$

disimpulkan dari (2.28) dan (2.35), persamaan Maxwell dalam tensor dapat ditulis

$$
\partial_{\nu} F^{\nu \mu}=-\mu_{0} J^{\mu} \quad \text { dan } \quad \partial_{\mu} \tilde{F}^{\nu \mu}=0
$$

Lebih dari itu, dapat pula dibentuk persamaan kontinuitas secara tensor, dimana persamaan kontinuitas ditulis

$$
\frac{\partial \rho}{\partial t}+\nabla \cdot J=\partial_{\mu} J^{\mu}=0
$$




\section{Lagrangian}

Lagrangian didefinisikan

$$
L \equiv T-V
$$

dimana $V(q ; t)$ adalah potensial, dan $T(\dot{q} ; t)$ adalah energi kinetik. Persamaan gerak fisika mematuhi hukum 'least action principle', dimana aksi didefinisikan sebagai

$$
S \equiv \int d t L(q, \dot{q} ; t)
$$

dikarenakan kita ingin batas awal dan akhir tetap sama (variasi hanya diantara keduanya), maka kondisi batas harus memenuhi

$$
\delta q(A)=\delta q(B)=0
$$

dengan prinsip aksi terkecil $\delta S=0$, maka

$$
\delta S=\int d t\left[\left(\frac{\partial L}{\partial q}\right)-\frac{d}{d t}\left(\frac{\partial L}{\partial \dot{q}}\right)\right] \delta q
$$

dengan di set $\delta S=0$, didapat persamaan euler-lagrange

$$
\left(\frac{\partial L}{\partial q}\right)-\frac{d}{d t}\left(\frac{\partial L}{\partial \dot{q}}\right)=0
$$

Sekarang misalkan pegas seperti pada gambar 2, memiliki energi kinetik dan potensial

$$
T=\frac{1}{2} \sum_{i} m \eta_{i}^{2} ; \quad V=\frac{1}{2} \sum_{i} k\left(\eta_{i+1}-\eta_{i}\right)^{2}
$$

dengan $\eta_{i}$ adalah simpangan massa pada posisi $i$. Lagrangian sistem adalah

$$
\begin{aligned}
L & =\frac{1}{2} \sum_{i} m \eta_{i}^{2}-\frac{1}{2} \sum_{i} k\left(\eta_{i+1}-\eta_{i}\right)^{2}=x \frac{1}{2} \sum_{i} \frac{m}{x} \eta_{i}^{2}-\frac{1}{2} \sum_{i} k x^{2}\left(\frac{\eta_{i+1}-\eta_{i}}{x}\right)^{2} \\
& =x \frac{1}{2} \sum_{i} \mu \eta_{i}^{2}-\frac{1}{2} \sum_{i} Y\left(\frac{\eta_{i+1}-\eta_{i}}{x}\right)^{2}
\end{aligned}
$$

dengan $\mu$ adalah rapat massa, dan $Y$ adalah modulus Young. Sekarang jika pada kasus ekstrim $x \rightarrow 0$, dan $N \rightarrow \infty$, maka

$$
L=\int d x\left(\frac{1}{2} \sum_{i} \mu \eta_{i}^{2}-\frac{1}{2} \sum_{i} Y\left(\frac{\partial \eta_{i}}{\partial x}\right)^{2}\right)=\int d x \mathcal{L}
$$

dengan $\mathcal{L}\left(\eta, \dot{\eta}, \frac{\partial \eta}{\partial x}\right)$ disebut rapat lagrangian. Rapat lagrangian selanjutnya akan digunakan untuk medan.

\subsection{Medan Skalar}

Sekarang kita konstruksi eular-lagrange untuk medan skalar $\mathcal{L}\left(\phi, \partial_{\mu} \phi\right)$. Dengan aksi

$$
S=\int d^{4} x \mathcal{L}\left(\phi, \partial_{\mu} \phi\right)
$$

Variasi aksi memberikan

$$
\begin{aligned}
\delta S & =\int d^{4} x\left[\frac{\partial \mathcal{L}}{\partial \phi} \delta \phi+\frac{\partial \mathcal{L}}{\partial\left(\partial_{\mu} \phi\right)} \delta\left(\partial_{\mu} \phi\right)\right] \\
& =\int d^{4} x\left\{\frac{\partial \mathcal{L}}{\partial \phi} \delta \phi+\partial_{\mu}\left[\frac{\partial \mathcal{L}}{\partial\left(\partial_{\mu} \phi\right)} \delta \phi\right]-\partial_{\mu}\left[\frac{\partial \mathcal{L}}{\partial\left(\partial_{\mu} \phi\right)}\right] \delta \phi\right\} \\
& =\int d^{4} x\left\{\frac{\partial \mathcal{L}}{\partial \phi}-\partial_{\mu}\left[\frac{\partial \mathcal{L}}{\partial\left(\partial_{\mu} \phi\right)}\right]\right\} \delta \phi
\end{aligned}
$$

mom-momprom

Gambar 2: Pegas 
maka persamaan euler-lagrange untuk medan

$$
\frac{\partial \mathcal{L}}{\partial \phi}-\partial_{\mu}\left[\frac{\partial \mathcal{L}}{\partial\left(\partial_{\mu} \phi\right)}\right]=0
$$

Lagrangian medan skalar yang paling sederhana adalah

$$
\mathcal{L}=\frac{1}{2}\left(\partial_{\mu} \phi\right)\left(\partial^{\mu} \phi\right)+\frac{1}{2} m^{2} \phi^{2}
$$

Lagrangian diatas memiliki sifat skalar, observable, suku kuadratnya merupakan derivatif order pertama, dan terdapat suku kuadratik. Maka euler-lagrange untuk lagrangian diatas adalah

$$
\begin{aligned}
\frac{\partial \mathcal{L}}{\partial\left(\partial_{\mu} \phi\right)} & =\frac{\partial}{\partial\left(\partial_{\mu} \phi\right)} \frac{1}{2}\left(\eta^{\alpha \beta} \partial_{\alpha} \phi \partial_{\beta} \phi\right)=\frac{1}{2} \eta^{\alpha \beta}\left(\delta_{\alpha}^{\mu} \partial_{\beta} \phi+\delta_{\beta}^{\mu} \partial_{\alpha} \phi\right) \\
& =\frac{1}{2}\left(\eta^{\mu \beta} \partial_{\beta} \phi+\eta^{\alpha \mu} \partial_{\alpha} \phi\right)=\frac{1}{2}\left(\partial^{\mu} \phi+\partial^{\mu} \phi\right)=\partial^{\mu} \phi
\end{aligned}
$$

maka

$$
\partial_{\mu}\left[\frac{\partial \mathcal{L}}{\partial\left(\partial_{\mu} \phi\right)}\right]=\partial_{\mu}\left(\partial^{\mu} \phi\right)=\square^{2} \phi
$$

didapat persamaan euler-lagrange total adalah

$$
\square^{2} \phi-m^{2} \phi=0 \quad \text { pers. klein gordon }
$$

Hal yang menarik adalah persamaan Schrodinger relativistik untuk partikel bebas merupakan pers. klein gordon. Dimana hamiltonian relativistik partikel bebas ditulis

$$
H_{0}=\sqrt{p^{2} c^{2}+m^{2} c^{4}}=\sqrt{p^{2}+m^{2}}
$$

dengan di set $c=\hbar=1$, maka

$$
\begin{aligned}
i \frac{\partial \psi}{\partial t} & =H_{0} \psi \quad \times i \frac{\partial}{\partial t} \\
-\frac{\partial^{2} \psi}{\partial t^{2}} & =i \frac{\partial}{\partial t}\left(H_{0} \psi\right)=H_{0}\left(i \frac{\partial \psi}{\partial t}\right)=H_{0}^{2} \psi=p^{2} \psi+m^{2} \psi=-\nabla^{2} \psi+m^{2} \psi
\end{aligned}
$$

didapat

$$
\square^{2} \psi-m^{2} \psi=0
$$

\subsection{Teorema Noether}

"Jika terdapat suatu sistem yang invarian terhadap suatu transformasi tertentu, maka ada kuantitas yang kekal."

Pembuktian: terdapat lagrangian

$$
\mathcal{L}=\mathcal{L}\left[\phi\left(x^{\mu}\right), \partial_{\mu} \phi\left(x^{\mu}\right) ; x^{\mu}\right]
$$

Jika kuantitas medan skalar di transformasi sedemikian rupa

$$
\phi \rightarrow \phi^{\prime}=\phi^{\prime}(\phi, \xi)
$$

dengan variabel kontinu $\xi$ adalah parameter tuning pada suatu transformasi yang dimana $\left(\phi^{\prime}(\phi, 0)=\phi\right)$. Ekspansi taylor lagrangian

$$
\mathcal{L}^{\prime}=\mathcal{L}+\xi \frac{\partial \mathcal{L}}{\partial \xi}+\ldots
$$


Jika transformasi invarian, maka

$$
\left.\xi \frac{\partial \mathcal{L}}{\partial \xi}\right|_{\xi=0}=0
$$

dapat ditulis

$$
\begin{aligned}
&\left.\frac{\partial \mathcal{L}}{\partial \phi^{\prime}} \frac{\partial \phi^{\prime}}{\partial \xi}\right|_{\xi=0}+\left.\frac{\partial \mathcal{L}}{\partial_{\mu}\left(\partial_{\mu} \phi^{\prime}\right)} \frac{\partial\left(\partial_{\mu} \phi^{\prime}\right)}{\partial \xi}\right|_{\xi=0}=\left.\partial_{\mu} \frac{\partial \mathcal{L}}{\partial\left(\partial_{\mu} \phi^{\prime}\right)} \frac{\partial \phi^{\prime}}{\partial \xi}\right|_{\xi=0}+\left.\frac{\partial \mathcal{L}}{\partial_{\mu}\left(\partial_{\mu} \phi^{\prime}\right)} \frac{\partial_{\mu}\left(\partial \phi^{\prime}\right)}{\partial \xi}\right|_{\xi=0} \\
&\left.\partial_{\mu}\left[\frac{\partial \mathcal{L}}{\partial\left(\partial_{\mu} \phi^{\prime}\right)} \frac{\partial \phi^{\prime}}{\partial \xi}\right]\right|_{\xi=0}=0
\end{aligned}
$$

Hal ini dapat dianalogikan dengan persamaan kontinuitas. Maka dari itu persamaan kontinuitas ini mengisyaratkan terdapat kuantitas total sistem yang kekal. Arus yang mengalir sistem lagrangian disebut sebagai arus noether ${ }^{8}$

${ }^{8}$ arus noether

Sekarang jika terdapat transformasi-4, dimana

$$
x^{\mu} \rightarrow x^{\prime \mu}=x^{\mu}+\xi \delta x^{\mu}
$$

transfromasi medan skalar memberikan

$$
\phi\left(x^{\nu}\right) \rightarrow \phi\left(x^{\prime \nu}\right)=\phi\left(x^{\nu}+\xi \delta x^{\nu}\right)=\phi\left(x^{\nu}\right)+\xi\left(\partial_{\mu} \phi\right) \delta x^{\nu}+\ldots
$$

dan lagrangian

$$
\mathcal{L} \rightarrow \mathcal{L}^{\prime}=\mathcal{L}^{\prime}\left[\phi\left(x^{\nu}+\xi \delta x^{\nu}\right), \partial_{\mu} \phi\left(x^{\nu}+\xi \delta x^{\nu}\right)\right]=\mathcal{L}+\xi\left(\partial_{\mu} \mathcal{L}\right) \delta x^{\nu}+\ldots
$$

ekuivalen dengan (3.18), maka

$$
\frac{\partial \mathcal{L}}{\partial \xi}=\left(\partial_{\mu} \mathcal{L}\right) \delta x^{\nu}
$$

suku ruas kiri dapat ditulis

$$
\partial_{\mu}\left[\frac{\partial \mathcal{L}}{\partial\left(\partial_{\mu} \phi^{\prime}\right)} \frac{\partial \phi^{\prime}}{\partial \xi}\right]=\left(\partial_{\mu} \mathcal{L}\right) \delta x^{\nu}
$$

suku $\frac{\partial \phi^{\prime}}{\partial \xi}$ ekuivalen dengan ekspansi orde-1 pada (3.18), sehingga

$$
\begin{aligned}
& \partial_{\mu}\left[\frac{\partial \mathcal{L}}{\partial\left(\partial_{\mu} \phi^{\prime}\right)} \partial_{\nu} \phi \delta x^{\nu}\right]=\left(\partial_{\mu} \mathcal{L}\right) \delta x^{\nu} \\
& \partial_{\mu}\left[\frac{\partial \mathcal{L}}{\partial\left(\partial_{\mu} \phi^{\prime}\right)} \partial_{\nu} \phi\right] \delta x^{\nu}+\left[\frac{\partial \mathcal{L}}{\partial\left(\partial_{\mu} \phi^{\prime}\right)} \partial_{\nu} \phi\right] \partial_{\mu}\left(\delta x^{\nu}\right)=\left(\partial_{\mu} \mathcal{L}\right) \delta x^{\nu}
\end{aligned}
$$

dikarenakan $\partial_{\mu}\left(\delta x^{\nu}\right)=\delta\left(\partial_{\mu} x^{\nu}\right)=\delta\left(\delta_{\mu}^{\nu}\right)=0$, didapat

$$
\partial_{\mu}\left[\frac{\partial \mathcal{L}}{\partial\left(\partial_{\mu} \phi\right)} \partial_{\nu} \phi-\partial_{\mu} \mathcal{L}\right] \delta x^{\nu}=0
$$

Sehingga

$$
\partial_{\mu}\left[\frac{\partial \mathcal{L}}{\partial\left(\partial_{\mu} \phi\right)} \partial_{\nu} \phi-\mathcal{L}\right]=\partial_{\mu} T_{\nu}^{\mu}=0
$$

dengan $T_{\nu}^{\mu}$ didefinisikan sebagai tensor energi-momentum. 


\subsection{Lagrangian Medan Maxwell}

Persamaan Maxwell dan identitas Bianchi ditulis

$$
\partial_{\mu} F^{\mu \nu}=-\mu_{0} j^{\nu} \quad \text { dan } \quad \partial_{\mu} \tilde{F}^{\mu \nu}=0
$$

Lalu bagaimana lagrangiannya? Lagrangian sebelumnya harus memiliki sifat skalar, riil, suku kinetik bersifat kuadratik dari derivatif orde pertama. Lagrangian dibutuhkan untuk mengetahui properti lebih luas dari sebuah sistem, dibanding hanya mengetahui persamaan Maxwell saja. Akan dibuktikkan bahwa lagrangian medan Maxwell adalah

$$
\mathcal{L}=-\frac{1}{4} F_{\mu \nu} F^{\mu \nu}+\mu_{0} J^{\mu} A_{\mu}
$$

dimana suku kinetik merupakan suku kuadratik dari turunan pertama vektor potensial $A_{\mu}$. Agar diatas memenuhi persamaan lagrangian medan maxwell, dilakukan reverse proof. Pertama ditulis dahulu aksinya

$$
S=\int d^{4} x \mathcal{L}\left(A_{\mu}, \partial_{\nu} A_{\mu}\right)
$$

terdapat dua cara pembuktian, pertama dengan euler-lagrange, kedua dengan pembuktian langsung dari aksi nya.

Euler-Lagrange Method Pertama dari euler lagrange, dapat dibentuk aksi

$$
\delta S=\int d^{4} x\left\{\frac{\partial \mathcal{L}}{\partial A_{\mu}} \delta A_{\mu}+\frac{\partial \mathcal{L}}{\partial\left(\partial_{\nu} A_{\mu}\right)} \delta\left(\partial_{\nu} A_{\mu}\right)\right\}
$$

suku kedua dapat dibentuk

$$
\frac{\partial \mathcal{L}}{\partial\left(\partial_{\nu} A_{\mu}\right)} \partial_{\nu}\left(\delta A_{\mu}\right)=\partial_{\nu}\left[\frac{\partial \mathcal{L}}{\partial\left(\partial_{\nu} A_{\mu}\right)} \delta A_{\mu}\right]-\partial_{\nu}\left[\frac{\partial \mathcal{L}}{\partial\left(\partial_{\nu} A_{\mu}\right)}\right] \delta A_{\mu}
$$

Suku pertama akan menghasilkan nilai integrasi nol, dikarenakan kondisi batas $\left.\delta A_{\mu}\right|_{\text {batas }}=$ 0 , sehingga

$$
\delta S=\int d^{4} x\left\{\frac{\partial \mathcal{L}}{\partial A_{\mu}}-\partial_{\nu}\left[\frac{\partial \mathcal{L}}{\partial\left(\partial_{\nu} A_{\mu}\right)}\right]\right\} \delta A_{\mu}
$$

didapat persamaan euler lagrange

$$
\frac{\partial \mathcal{L}}{\partial A_{\mu}}-\partial_{\nu} \frac{\partial \mathcal{L}}{\partial\left(\partial_{\nu} A_{\mu}\right)}=0
$$

dengan lagrangian diberikan pada (3.22), didapat

$$
\frac{\partial \mathcal{L}}{\partial A_{\mu}}=\mu_{0} J^{\mu} \quad \text { dan } \quad \frac{\partial \mathcal{L}}{\partial\left(\partial_{\nu} A_{\mu}\right)}=-\frac{1}{4} \frac{\partial}{\partial\left(\partial_{\nu} A_{\mu}\right)}\left(F_{\alpha \beta} F^{\alpha \beta}\right)
$$

Dari euler-lagrange ini akan terkonfirmasi (Lihat Lampiran 4) persamaan maxwell.

$$
\partial_{\nu} F^{\nu \mu}=-\mu_{0} J^{\mu}
$$

Evaluating Action Method cara kedua tanpa dari euler-lagrange, kita dapat membuktikkannya langsung dari prinsip aksi terkecil $\delta S=0$, dimana

$$
\delta S=\frac{1}{4} \int d^{4} x \delta\left(F_{\mu \nu} F^{\nu \mu}\right)+\mu_{0} \int d^{4} x J^{\mu} \delta\left(A_{\mu}\right)
$$

nilai $\delta\left(F_{\mu \nu} F^{\nu \mu}\right)$ memberikan

$$
\begin{aligned}
\delta\left(F_{\mu \nu} F^{\nu \mu}\right) & =\left(\delta F_{\mu \nu}\right) F^{\mu \nu}+F_{\mu \nu}\left(\delta F^{\mu \nu}\right)=\left(\delta F_{\mu \nu}\right) F^{\mu \nu}+\eta_{\alpha \mu} \eta_{\beta \nu} F^{\alpha \beta}\left(\delta F^{\mu \nu}\right) \\
& =\left(\delta F_{\mu \nu}\right) F^{\mu \nu}+F^{\alpha \beta}\left(\delta F_{\alpha \beta}\right)=2 \delta\left(F_{\mu \nu}\right) F^{\mu \nu}
\end{aligned}
$$

Subtitusi ini ke dalam variasi aksi, akan terkonfirmasi (Lihat Lampiran 5) kembali persamaan maxwell

$$
\partial_{\nu} F^{\nu \mu}=-\mu_{0} J^{\mu}
$$




\subsection{Invariansi medan skalar kompleks}

Jika terdapat medan skalar yang bersifat kompleks, dengan

$$
\phi=\frac{1}{\sqrt{2}}\left(\phi_{1}+i \phi_{2}\right) \quad \text { dan } \quad \phi^{\dagger}=\frac{1}{\sqrt{2}}\left(\phi_{1}-i \phi_{2}\right)
$$

Maka memiliki lagrangian

$$
\mathcal{L}=\partial_{\mu} \phi^{\dagger} \partial^{\mu} \phi-m^{2} \phi^{\dagger} \phi
$$

memberikan persamaan euler-lagrange untuk masin-masing,

$$
\frac{\partial \mathcal{L}}{\partial \phi^{\dagger}}-\partial_{\mu} \frac{\partial \mathcal{L}}{\partial\left(\partial_{\mu} \phi^{\dagger}\right)}=0 \quad \text { dan } \quad \frac{\partial \mathcal{L}}{\partial \phi}-\partial_{\mu} \frac{\partial \mathcal{L}}{\partial\left(\partial_{\mu} \phi\right)}=0
$$

menghasilkan solusi pers. klein gordon untuk keduanya

$$
\square^{2} \phi-m^{2} \phi=0 \quad \text { dan } \quad \square^{2} \phi^{\dagger}-m^{2} \phi^{\dagger}=0
$$

Jika dilakukan transformasi sedemikian rupa dengan $\phi \rightarrow \phi^{\prime} \equiv \mathcal{U} \phi$, dimana $\mathcal{U}$ adalah parameter transformasi yang memenuhi sifat unitary $\mathcal{U}^{\dagger} \mathcal{U}=1$. Dengan mengambil bentuk sederhana $\mathcal{U}$ dengan

$$
\mathcal{U}=e^{i \alpha} \operatorname{dan} \mathcal{U}^{\dagger}=e^{-i \alpha}
$$

Jika $\alpha$ adalah sebuah angka, maka dapat dilihat sebagai matriks $(1 \times 1)$. Ini disebut sebagai grup $U(1)$. Transformasi ini ditulis

$$
\phi \rightarrow \phi^{\prime}=U \phi=e^{i \alpha} \phi \quad \text { dan } \quad \phi^{\dagger} \rightarrow \phi^{\prime \dagger}=\phi^{\dagger} U^{\dagger}=\phi^{\dagger} e^{-i \alpha}
$$

\section{Transformasi Global}

Untuk transformasi global, maka $\alpha=$ konst. Sehingga mudah dilihat bahwa lagrangian invariansi terhadap transformasi global. Arus noether dalam hal ini juga harus kekal ${ }^{9}$. Transformasi medan skalar dapat ditulis sebagai

$$
\phi \rightarrow \phi^{\prime}=\phi+\delta \phi \quad \text { dan } \quad \phi^{\dagger} \rightarrow \phi^{\prime \dagger}=\phi^{\dagger}+\delta \phi^{\dagger}
$$

${ }^{9}$ Arus noether

$$
J^{\mu}=\frac{\partial \mathcal{L}}{\partial\left(\partial_{\mu} \phi\right)} \delta \phi+\frac{\partial \mathcal{L}}{\partial\left(\partial_{\mu} \phi^{\dagger}\right)} \delta \phi^{\dagger}
$$

Jika $\alpha$ infinitesimal, $e^{i \alpha} \cong 1+i \alpha$, maka

$$
\delta \phi=i \alpha \phi ; \quad \text { dan } \quad \delta \phi^{\dagger}=-i \alpha \phi^{\dagger}
$$

Sehingga arus noether

$$
J^{\mu}=\frac{\partial \mathcal{L}}{\partial\left(\partial_{\mu} \phi\right)} i \alpha \phi-\frac{\partial \mathcal{L}}{\partial\left(\partial_{\mu} \phi^{*}\right)} i \alpha \phi^{\dagger}
$$

subtitusi lagrangian, didapat

$$
J^{\mu}=i \alpha\left(\partial^{\mu} \phi^{\dagger} \phi-\partial^{\mu} \phi \phi^{\dagger}\right)
$$

maka persamaan kontinuitas memberikan

$$
\partial_{\mu} J^{\mu}=i \alpha\left[\left(\partial_{\mu} \partial^{\mu} \phi^{*}\right) \phi+\left(\partial^{\mu} \phi^{*}\right)\left(\partial_{\mu} \phi\right)-\left(\partial_{\mu} \partial^{\mu} \phi\right) \phi^{\dagger}-\left(\partial^{\mu} \phi^{\dagger}\right)\left(\partial_{\mu} \phi\right)\right]
$$

dikarenakan $\left(\partial^{\mu} \phi^{\dagger}\right)\left(\partial_{\mu} \phi\right)=\left(\partial^{\mu} \phi^{\dagger}\right)\left(\partial_{\mu} \phi\right)$, maka ${ }^{10}$

$$
\partial_{\mu} J^{\mu}=i \alpha\left[\left(\partial_{\mu} \partial^{\mu} \phi^{\dagger}\right) \phi-\left(\partial_{\mu} \partial^{\mu} \phi\right) \phi^{\dagger}\right]=i \alpha\left[m^{2} \phi^{\dagger} \phi-m^{2} \phi \phi^{\dagger}\right]=0
$$

10 terbukti terdapat arus noether kekal dalam transformasi global 


\section{Transformasi Lokal}

Untuk $\mathcal{U}(1)$ gauge/lokal, kuantitas tidak lagi konstan, $\alpha=\alpha\left(x^{\mu}\right)$. Lagrangian dalam transformasi ini

$$
\mathcal{L}^{\prime}=\partial_{\mu} \phi^{\dagger \dagger} \partial^{\mu} \phi^{\prime}-m^{2} \phi^{\prime \dagger} \phi^{\prime}
$$

Pada suku pertama ${ }^{11}$

$$
\begin{aligned}
\partial_{\mu} \phi^{\prime \dagger} \partial^{\mu} \phi^{\prime} & =\partial_{\mu}\left(\phi^{\dagger} e^{-i \alpha}\right) \partial^{\mu}\left(e^{i \alpha} \phi\right)=\left[\partial_{\mu} \phi^{\dagger}-i \phi^{\dagger}\left(\partial_{\mu} \alpha\right)\right] e^{-i \alpha}\left[\partial^{\mu} \phi+i\left(\partial^{\mu} \alpha\right) \phi\right] e^{i \alpha} \\
& =\partial_{\mu} \phi^{\dagger} \partial^{\mu} \phi+i\left(\partial^{\mu} \alpha\right)\left(\partial_{\mu} \phi^{\dagger}\right) \phi-i\left(\partial_{\mu} \alpha\right) \phi^{\dagger} \partial^{\mu} \phi-\left(\partial_{\mu} \alpha\right)\left(\partial^{\mu} \alpha\right) \phi^{\dagger} \phi
\end{aligned}
$$

${ }^{11}$ suku kedua, jelas memberikan

$$
\begin{aligned}
m^{2} \phi^{\dagger \dagger} \phi^{\prime} & =m^{2}\left(\phi^{\dagger} e^{-i \alpha}\right)\left(e^{i \alpha} \phi\right) \\
& =m^{2} \phi^{\dagger} \phi
\end{aligned}
$$

Dilihat bahwa lagrangian tidak invarian terhadap transformasi lokal, hal ini dikarenakan $\partial_{\mu} \phi^{\prime} \neq \mathcal{U} \partial_{\mu} \phi$. Kita menginginkan agar suku pertamanya dapat invarian terhadap trasnformasi, dimana terdapat $D_{\mu} \phi^{\prime}=D_{\mu}(U \phi)=U D_{\mu} \phi$. Agar invarian, maka didefinisikan bentuk derivasi lain sebagai

$$
D_{\mu} \equiv \partial_{\mu}+i q X_{\mu}
$$

dengan $q=$ konstan. Hal ini dilakukan agar kita dapat menemukan sistem fisika (lagrangian) yang invarian terhadap transformasi lokal. $X_{\mu} \rightarrow X_{\mu}^{\prime}$ bertransformasi jika medan skalar ditransformasikan. Maka

$$
\begin{aligned}
\partial_{\mu} \phi^{\prime}+i q X_{\mu}^{\prime} \phi^{\prime} & =U\left(\partial_{\mu} \phi+i q X_{\mu} \phi\right) \\
e^{-i \alpha}\left[\partial_{\mu} \phi-\left(\partial_{\mu} \alpha\right) \phi+i q X_{\mu}^{\prime} \phi\right] & =e^{-i \alpha}\left[\partial_{\mu} \phi+i q X_{\mu} \phi\right]
\end{aligned}
$$

didapat

$$
X_{\mu}^{\prime}=X_{\mu}+\frac{1}{q} \partial_{\mu} \alpha
$$

Dari hal ini, dikonstruksi lagrangian baru, dimana

$\mathcal{L}=\left(D_{\mu} \phi\right)^{\dagger}\left(D^{\mu} \phi\right)-m^{2} \phi^{\dagger} \phi=\partial_{\mu} \phi^{\dagger} \partial^{\mu} \phi+i q\left[X^{\mu}\left(\partial_{\mu} \phi^{\dagger}\right) \phi-X_{\mu} \phi^{\dagger} \partial^{\mu} \phi\right]+q^{2} X_{\mu} X^{\mu} \phi^{\dagger} \phi-m^{2} \phi^{\dagger} \phi$

perhatikan lagrangian ini dapat kita lihat sebagai medan skalar berinteraksi dengan medan lain, $X^{\mu}$. Maka medan ini seharusnya juga memiliki suku kinetiknya (yang tentu harus juga invarian terhadap transformasi lokal), akan didapat bahwa suku kinetik medan ini adalah

$$
\mathcal{L}_{\text {kin }} \sim\left(\partial_{\mu} X_{\nu}-\partial_{\nu} X_{\mu}\right)\left(\partial^{\mu} X^{\nu}-\partial^{\nu} X^{\mu}\right)
$$

dimana transformasi terbukti invarian, yakni

$\partial_{\mu} X_{\nu}^{\prime}-\partial_{\nu} X_{\mu}^{\prime}=\partial_{\mu}\left(X_{\nu}+\frac{1}{q} \partial_{\nu} \alpha\right)-\partial_{\nu}\left(X_{\mu}+\frac{1}{q} \partial_{\mu} \alpha\right)=\partial_{\mu} X_{\nu}-\partial_{\nu} X_{\mu}+\frac{1}{q}\left(\partial_{\mu} \partial_{\nu} \alpha-\partial_{\nu} \partial_{\mu} \alpha\right)=\partial_{\mu} X_{\nu}-\partial_{\nu} X_{\mu}$

Perhatikan bahwa (3.45) tidak lain tidak bukan adalah tensor medan maxwell. Sehingga disimpulkan, lagrangian yang invarian terhadap transformasi lokal adalah medan skalar yang berinteraksi dengan medan maxwell, yakni

$$
\mathcal{L}=\left(D_{\mu} \phi\right)^{\dagger}\left(D^{\mu} \phi\right)-m^{2} \phi^{\dagger} \phi-\frac{1}{4} F_{\mu \nu} F^{\mu \nu}
$$

sehingga $X_{\nu}$ tidak lain tidak bukan adalah $A_{\nu}$. 


\section{Teori Gauge non-Abelian}

Teori non-Abelian gauge adalah elemen transformasi lokalnya tidak memenuhi komutasi. Misalkan transformasi rotasi pada tiga dimensi, rotasi terhadap sumbu $\mathrm{x}$ dahulu baru $\mathrm{y}$ kemudian menghasilkan hasil yang berbeda terhadap sumbu y dahulu baru $\times$ kemudian, dimana

$$
R_{x}(\pi / 2) R_{y}(\pi / 2) \neq R_{y}(\pi / 2) R_{x}(\pi / 2)
$$

Hal ini berkaitan dengan proses operasi matriks. Matriks rotasi sendiri terhadap masingmasing sumbu didapat

$R_{z}(\alpha)=\left(\begin{array}{ccc}\cos \alpha & \sin \alpha & 0 \\ -\sin \alpha & \cos \alpha & 0 \\ 0 & 0 & 1\end{array}\right) ; \quad R_{x}(\alpha)=\left(\begin{array}{ccc}1 & 0 & 0 \\ 0 & \cos \alpha & \sin \alpha \\ 0 & -\sin \alpha & \cos \alpha\end{array}\right) ; \quad R_{y}(\alpha)=\left(\begin{array}{ccc}\cos \alpha & 0 & -\sin \alpha \\ 0 & 1 & 0 \\ \sin \alpha & 0 & \cos \alpha\end{array}\right)$

Jelas ketiga matriks tersebut tidak memenuhi komutasi. Sekarang, jika dilakukan rotasi dengan sudut infinitesimal $\alpha$, pada ekspansi orde terendah didapat

$$
R_{z}(\alpha)=\left(\begin{array}{ccc}
1 & 0 & 0 \\
0 & 1 & 0 \\
0 & 0 & 1
\end{array}\right)+\alpha\left(\begin{array}{ccc}
0 & 1 & 0 \\
-1 & 0 & 0 \\
0 & 0 & 0
\end{array}\right)=1+i J_{z} \alpha
$$

dimana $J_{z}$ dapat dilihat sebagai matriks generator untuk rotasi pada sumbu-z, dengan

$$
J_{z}=\left(\begin{array}{ccc}
0 & -i & 0 \\
i & 0 & 0 \\
0 & 0 & 0
\end{array}\right) ; \quad J_{x}=\left(\begin{array}{ccc}
0 & 0 & 0 \\
0 & 0 & -i \\
0 & i & 0
\end{array}\right) ; \quad J_{y}=\left(\begin{array}{ccc}
0 & 0 & i \\
0 & 0 & 0 \\
-i & 0 & 0
\end{array}\right)
$$

matriks generator diatas juga tidak saling komutasi. Dapat ditunjukkan bahwa

$$
\left[J_{x}, J_{y}\right]=i \epsilon^{x y z} J_{z}
$$

Dari persamaan (4.2), rotasi dengan sudut berhingga, dapat digeneralisasi sebagai

$$
R_{z}(\alpha)=\exp \left(i J_{z} \alpha\right)
$$

Namun, kita tidak ingin berbicara untuk grup transformasi rotasi $\mathrm{SO}(3)$. Kita lebih tertarik pada representasi untuk SU(2). Pada SU(2), persamaan (107) di ekspresikan sebagai

$$
\mathcal{U}=\exp \left[-i\left(\frac{\sigma^{b}}{2} a^{b}\right)\right]
$$

dimana $\sigma^{b}$ merupakan matriks pauli

$$
\sigma^{1}=\left(\begin{array}{cc}
0 & 1 \\
1 & 0
\end{array}\right) ; \sigma^{2}=\left(\begin{array}{cc}
0 & -i \\
i & 0
\end{array}\right) ; \sigma^{3}=\left(\begin{array}{cc}
1 & 0 \\
0 & -1
\end{array}\right)
$$

dimana matriks pauli, memenuhi relasi

$$
\left(\sigma^{a}\right)^{\dagger}=\sigma^{a} ; \quad\left[\sigma^{a}, \sigma^{b}\right]=2 i \epsilon^{a b c} \sigma^{c} ; \quad\left\{\sigma^{a}, \sigma^{b}\right\}=\sigma^{a} \sigma^{b}+\sigma^{b} \sigma^{a}=2 \delta^{a b}
$$

ini memberikan konsekuensi matematis berupa ${ }^{12}$

12 juga memberikan

$$
\sigma^{a} \sigma^{b}=\frac{1}{2}\left(\left[\sigma^{a}, \sigma^{b}\right]+\left\{\sigma^{a}, \sigma^{b}\right\}\right)=\delta^{a b}+i \epsilon^{a b c} \sigma^{c}
$$

maka dengan mengekspansi (4.6),

$$
\begin{aligned}
(\sigma \cdot A)(\sigma \cdot B) & =\sigma^{a} \sigma^{b} A^{a} B^{b} \\
& =A \cdot B+i \sigma^{c}(A \times B)
\end{aligned}
$$

$$
\mathcal{U}=1-i \frac{\sigma^{b}}{2} a^{b}+\frac{1}{2}\left(i \frac{\sigma^{b}}{2} a^{b}\right)^{2}-\ldots
$$


sehingga akan didapat ${ }^{13}$

$$
\mathcal{U}=1-\frac{i}{2} a(\sigma \cdot \hat{n})-\frac{1}{8} a^{2}+\frac{i}{3 !}\left(\frac{a}{2}\right)^{3}(\sigma \cdot \hat{n})+\ldots=\cos \left(\frac{a}{2}\right)-i(\sigma \cdot \hat{n}) \sin \left(\frac{a}{2}\right)
$$

Perhatikan transformasi ini tetap memenuhi sifat unitary. Misalkan untuk $U_{z}$,

$$
\mathcal{U}=\cos \left(\frac{a}{2}\right)+\left(\begin{array}{cc}
-i & 0 \\
0 & i
\end{array}\right) \sin \left(\frac{a}{2}\right)=\left(\begin{array}{cc}
e^{-i a / 2} & 0 \\
0 & e^{i a / 2}
\end{array}\right)
$$

\section{Transformasi SU(2) Global}

Sekarang kita ingin melihat bagaimana lagrangian bertransformasi dengan transformasi grup SU(2) diatas. Untuk global, maka $a=$ konst. Dapat dibuktikkan bahwa

$$
\mathcal{L}^{\prime}=\partial_{\mu} \phi^{\dagger \dagger} \partial^{\mu} \phi^{\prime}-m^{2} \phi^{\prime \dagger} \phi^{\prime}=\partial_{\mu} \phi^{\dagger} \mathcal{U}^{\dagger} \mathcal{U} \partial^{\mu} \phi-m^{2} \phi^{\dagger} \mathcal{U}^{\dagger} \mathcal{U} \phi=\mathcal{L}
$$

\section{Transformasi SU(2) Lokal}

Untuk transformasi lokal dengan $a^{\prime \nu}\left(a^{\mu}\right)$. Dengan suku pertama mengambil bentuk derivasi (3.43). Maka

$$
\left(D_{\mu} \phi\right)^{\prime}=\mathcal{U}\left(D_{\mu} \phi\right) \rightarrow \partial_{\mu}(\mathcal{U} \phi)+i g A_{\mu}^{\prime} \mathcal{U} \phi=\mathcal{U}\left(\partial_{\mu} \phi\right)+i g \mathcal{U}\left(A_{\mu} \phi\right)
$$

akan didapat transformasi $A_{\mu}^{\prime}$ menjadi

$$
A_{\mu}^{\prime}=\mathcal{U} A_{\mu} \mathcal{U}^{\dagger}+\frac{i}{g}\left(\partial_{\mu} \mathcal{U}\right) \mathcal{U}^{\dagger}
$$

Pada SU(2) ini, $A_{\mu}=A_{\mu}^{a} \frac{\sigma^{a}}{2}$. Maka transformasinya menjadi

$$
A_{\mu}^{\prime a} \frac{\sigma^{a}}{2}=\mathcal{U} A_{\mu}^{a} \frac{\sigma^{a}}{2} \mathcal{U}^{\dagger}+\frac{i}{g}\left(\partial_{\mu} \mathcal{U}\right) \mathcal{U}^{\dagger}=A_{\mu}^{a} \mathcal{U} \frac{\sigma^{a}}{2} \mathcal{U}^{\dagger}+\frac{i}{g}\left(\partial_{\mu} \mathcal{U}\right) \mathcal{U}^{\dagger}
$$

Pada kasus infinitesimal ${ }^{14} a^{b}$. Maka transformasi diatas, pada suku pertama ruas kanan dapat ditulis (dengan hanya mempertimbangkan orde pertama $a$ )

$$
\begin{aligned}
\mathcal{U} \frac{\sigma^{b}}{2} \mathcal{U}^{\dagger} & =\left(1-\frac{i}{2} \sigma^{b} a^{b}\right) \frac{\sigma^{c}}{2}\left(1+\frac{i}{2} \sigma^{d} a^{d}\right) \\
& =\frac{1}{2}\left(\sigma^{c}+\frac{i}{2}\left(\delta^{c d}+i \epsilon^{c d e} \sigma^{e}\right) a^{d}-\frac{i}{2}\left(\delta^{b c}+i \epsilon^{b c d} \sigma^{d}\right) a^{b}\right)
\end{aligned}
$$

dengan menggunakan trik penukaran indeks, akan didapat suku pertama menjadi

$$
A_{\mu}^{c} \mathcal{U} \frac{\sigma^{c}}{2} \mathcal{U}^{\dagger}=A_{\mu}^{c} \frac{\sigma^{c}}{2}-\frac{1}{2} A_{\mu}^{c} \epsilon^{c d e} \sigma^{e} a^{d}
$$

Lalu, suku kedua menjadi

$$
\frac{i}{g}\left(\partial_{\mu} \mathcal{U}\right) \mathcal{U}^{\dagger}=\frac{i}{g}\left[\partial_{\mu}\left(1-\frac{i}{2} \sigma^{b} a^{b}\right)\right]\left(1+\frac{i}{2} \sigma^{c} a^{c}\right)=\frac{i}{2 g} \sigma^{b} \partial_{\mu} a^{b}
$$

sehingga pada kasus infinitesimal, pers.(4.14) dapat ditulis kembali menjadi

$$
A_{\mu}^{\prime c} \frac{\sigma^{c}}{2}=A_{\mu}^{c} \frac{\sigma^{c}}{2}-\frac{1}{2} A_{\mu}^{c} \epsilon^{c d e} \sigma^{e} a^{d}+\frac{i}{2 g} \sigma^{c} \partial_{\mu} a^{c}
$$

Sekarang, setelah mendapatkan nilai $A_{\mu}^{\prime}$ pada kasus non-abelian, kita juga harus dapat membentuk medan tensor $F_{\mu \nu}$ pada non-abelian. Ini didefinisikan sebagai

$$
F_{\mu \nu}=\frac{1}{i g}\left[D_{\mu}, D_{\nu}\right]
$$


dengan turunan aljabar (Lihat Lampiran 6), akan didapat

$$
F_{\mu \nu}=\partial_{\mu} A_{\nu}-\partial_{\nu} A_{\mu}+i g\left[A_{\mu}, A_{\nu}\right]
$$

dikarenakan SU(2), $F_{\mu \nu}=F_{\mu \nu}^{c} \frac{\sigma^{c}}{2}$, dan $A_{\mu}=A_{\mu}^{c} \frac{\sigma^{c}}{2}$, maka dengan bentuk ini, medan tensor dapat ditulis*

$$
F_{\mu \nu}^{c}=\partial_{\mu} A_{\nu}^{c}-\partial_{\mu} A_{\mu}^{c}-g \epsilon^{a b c} A_{\mu}^{a} A_{\nu}^{b}
$$

Lagrangian yang invarian terhadap transformasi gauge SU(2) ini ditulis ${ }^{15}$

$$
\mathcal{L}=\left(D_{\mu} \phi\right)^{\dagger}\left(D^{\mu} \phi\right)-m^{2} \phi^{\dagger} \phi-\frac{1}{2} \operatorname{tr}\left(F_{\mu \nu} F^{\mu \nu}\right)
$$

disebut sebagai lagrangian Yang-Mills.

\section{Medan Gravitasi}

\subsection{Pendahuluan}

Sebelum menjelaskan lebih jauh mengenai medan gravitasi, perlu diketahui lebih dahulu catatan penting mengenai gravitasi. Pertama adalah prinsip ekuivalensi, dan kedua geodesik cahaya dan kelengkungan ruangwaktu.

Prinsip Ekuivalensi menyatakan bahwa massa inersial dalam hukum newtonian dan massa gravitasi sebagai penyebab munculnya gravitasi adalah sama. Misalkan pengamat $N$ berada pada kerangka yang bergerak non-relativistik dan berada dibawah pengaruh gaya $F\left(x_{N}-x_{M}\right)$, dan medan gravitasi $g$. Maka persamaan gerak pengamat itu adalah

$$
m_{N} \frac{d^{2} x_{N}}{d t^{2}}=m_{N} g+\sum_{m} F\left(x_{N}-x_{M}\right)
$$

Sekarang misalkan terdapat pengamat lain pada kerangka non-galilean

$$
x^{\prime}=x-\frac{1}{2} g t^{2} ; \quad t=t^{\prime}
$$

Maka persamaan gaya yang diukur pengamat lain adalah

$$
m_{N} \frac{d^{2} x_{N}^{\prime}}{d t^{2}}=\sum_{m} F\left(x_{N}^{\prime}-x_{M}^{\prime}\right)
$$

Pengamat dalam kerangka $x$ dan kerangka $x^{\prime}$ tidak menemukan adanya perbedaan pada persamaan gerak, atau secara umum hukum mekanika, hanya saja kerangka pada $x$ dia merasakan gaya gravitasi. Prinsip ini memberikan pernyataan bahwa medan gravitasi dapat di-cancel (ekuivalen) dengan gaya inersial, sehingga

$$
m_{f} a=G \frac{M m_{g}}{r^{2}} ; \quad \text { dengan } \quad m_{g}=m_{f}
$$

Kelengkungan Ruang Waktu. Telah diketahui bahwa cahaya bergerak dengan mengikuti lintasan geodesiknya, yakni lintasan dengan jarak terdekat. Pada ketiadaan medan gravitasi, pengamat melihat bahwa cahaya melintasi garis lurus antar dua titik, namun, pada saat diberi medan gravitasi yang kuat, atau ekuivalen dengan roket yang diberi percepatan yang sangat besar, lintasan cahaya teramati tidak lagi bergerak dengan lintasan garis lurus. Jika cahaya benar mengikuti lintasan geodesik pada ruang, maka dengan tidak lurusnya lintasan, ruang itu sendiri tidak lagi datar.

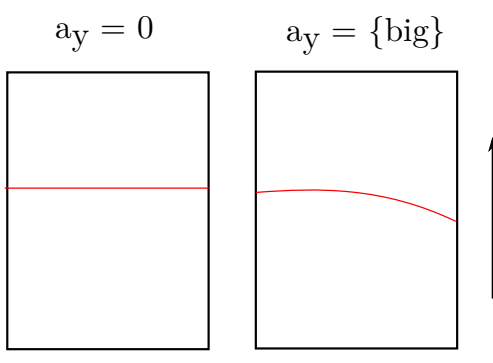

Gambar 3: Lintasan cahaya pada pengaruh percepatan (harus sangat besar untuk dapat diamati dengan mata telanjang) tidak lagi datar. Ini mengindikasikan adanya kelengkungan ruang waktu, dikarenakan cahaya mengikuti geodesik ruang. 
Ruang lengkung akan dilihat dari metriknya. Pertama, geodesik suatu ruang dinyatakan sebagai

$$
d s^{2}=\eta_{\mu \nu} d x^{\mu} d x^{\nu}
$$

masing-masing pada koordinat kartesian, silinder dan bola adalah

$$
\eta_{\mu \nu}=\operatorname{diag}(-1,1,1,1) ; \quad \eta_{\mu \nu}=\operatorname{diag}\left(-1,1, \rho^{2}, 1\right) ; \quad \eta_{\mu \nu}=\operatorname{diag}\left(-1,1, r^{2}, r^{2} \sin ^{2} \theta\right) ;
$$

Pada ruang datar terpenuhi bahwa $\partial_{\alpha} \eta_{\mu \nu}=0$, namun pada ruang yang lengkung derivasi metriknya tidak bernilai nol $\partial_{\alpha} \eta_{\mu \nu} \neq 0$. Sehingga notasi metrik ruang lengkung ini kita tulis sebagai $g_{\mu \nu}$ dibanding $\eta_{\mu \nu} . g_{\mu \nu}$ disebut sebagai Tensor Metrik Riemannian, dimana Riemannian adalah ruang yang lebih umum dari euclidean.

\subsection{Simbol Christoffel}

Simbol Christoffel merupakan notasi matematis yang penting dalam melakukan formulasi medan gravitasi pada relativitas umum. Berikut akan dijabarkan lebih dalam karakteristik matematis dari simbol christoffel.

Simbol Christoffel jenis pertama didefinisikan sebagai ${ }^{16}$

$$
\Gamma_{\alpha \rho \sigma} \equiv \frac{1}{2}\left(g_{\alpha \rho, \sigma}+g_{\alpha \sigma, \rho}-g_{\rho \sigma, \alpha}\right)
$$

simetri pada $\Gamma_{\alpha \rho \sigma}=\Gamma_{\alpha \sigma \rho}$. Christoffel jenis kedua didefinisikan ${ }^{17}$ sebagai

$$
\Gamma_{\rho \sigma}^{\alpha}=g^{\alpha \beta} \Gamma_{\beta \rho \sigma}=\frac{1}{2} g^{\alpha \beta}\left(g_{\beta \rho, \sigma}+g_{\beta \sigma, \rho}-g_{\rho \sigma, \beta}\right)
$$

Dari sini pula dapat kita ambil relasi penting,

$$
g_{\alpha \beta, \rho}=\Gamma_{\alpha \beta \rho}+\Gamma_{\beta \alpha \rho}
$$

${ }^{16}$ notasi derivatif

$$
g_{\mu \nu, \tau}=\partial_{\tau} g_{\mu \nu}=\frac{\partial g_{\mu \nu}}{\partial x^{\tau}}
$$

17 Jenis kedua ini juga disebut sebagai affine connection pada geometri Riemannian. Terlihat bahwa jenis kedua tidak simetri

$$
\Gamma_{\rho \sigma}^{\alpha} \neq \Gamma_{\sigma \rho}^{\alpha}
$$

Lalu apakah $\Gamma_{\alpha \rho \sigma}$ dan $\Gamma_{\rho \sigma}^{\alpha}$ adalah tensor rank-3? Untuk jenis pertama, dilakukan transformasi

$$
\begin{aligned}
\Gamma_{\alpha \rho \sigma}^{\prime}= & \frac{1}{2}\left(\frac{\partial g_{\alpha \rho}^{\prime}}{\partial x^{\prime \sigma}}+\frac{\partial g_{\alpha \sigma}^{\prime}}{\partial x^{\prime \rho}}-\frac{\partial g_{\rho \sigma}^{\prime}}{\partial x^{\prime \alpha}}\right) \\
= & \frac{1}{2}\left[\frac{\partial}{\partial x^{\prime \sigma}}\left(\frac{\partial x^{\mu}}{\partial x^{\prime \alpha}} \frac{\partial x^{\nu}}{x^{\prime \rho}} g_{\mu \nu}\right)+\frac{\partial}{\partial x^{\prime \rho}}\left(\frac{\partial x^{\mu}}{\partial x^{\prime \alpha}} \frac{\partial x^{\nu}}{x^{\prime \sigma}} g_{\mu \nu}\right)-\frac{\partial}{\partial x^{\prime \alpha}}\left(\frac{\partial x^{\mu}}{\partial x^{\prime \rho}} \frac{\partial x^{\nu}}{x^{\prime \sigma}} g_{\mu \nu}\right)\right] \\
= & \frac{1}{2}\left(\frac{\partial x^{\mu}}{\partial x^{\prime \alpha}} \frac{\partial x^{\nu}}{x^{\prime \rho}} \frac{\partial g_{\mu \nu}}{\partial x^{\prime \sigma}}+\frac{\partial x^{\mu}}{\partial x^{\prime \alpha}} \frac{\partial x^{\nu}}{x^{\prime \sigma}} \frac{\partial g_{\mu \nu}}{\partial x^{\prime \rho}}-\frac{\partial x^{\mu}}{\partial x^{\prime \rho}} \frac{\partial x^{\nu}}{x^{\prime \sigma}} \frac{\partial g_{\mu \nu}}{\partial x^{\prime \alpha}}\right) \\
& +\left[\frac{\partial}{\partial x^{\prime \sigma}}\left(\frac{\partial x^{\mu}}{\partial x^{\prime \alpha}} \frac{\partial x^{\nu}}{\partial x^{\prime \rho}}\right)+\frac{\partial}{\partial x^{\prime \rho}}\left(\frac{\partial x^{\mu}}{\partial x^{\prime \alpha}} \frac{\partial x^{\nu}}{\partial x^{\prime \sigma}}\right)-\frac{\partial}{\partial x^{\prime \alpha}}\left(\frac{\partial x^{\mu}}{\partial x^{\prime \rho}} \frac{\partial x^{\nu}}{\partial x^{\prime \sigma}}\right)\right] g_{\mu \nu}
\end{aligned}
$$

Suku pertama ruas kanan dapat dibentuk

$$
\text { suku pertama }=\frac{1}{2}\left(\frac{\partial x^{\mu}}{\partial x^{\prime \alpha}} \frac{\partial x^{\nu}}{x^{\prime \rho}} \frac{\partial x^{\kappa}}{\partial x^{\prime \sigma}}+\frac{\partial x^{\mu}}{\partial x^{\prime \alpha}} \frac{\partial x^{\nu}}{x^{\prime \sigma}} \frac{\partial x^{\kappa}}{\partial x^{\prime \rho}}-\frac{\partial x^{\mu}}{\partial x^{\prime \rho}} \frac{\partial x^{\nu}}{x^{\prime \sigma}} \frac{\partial x^{\kappa}}{\partial x^{\prime \alpha}}\right) \frac{\partial g_{\mu \nu}}{\partial x^{\kappa}}
$$

dengan melakukan trik penukaran indeks, dapat ditulis

$$
\text { suku pertama }=\frac{1}{2} \frac{\partial x^{\kappa}}{\partial x^{\prime \alpha}} \frac{\partial x^{\mu}}{\partial x^{\prime \rho}} \frac{\partial x^{\nu}}{\partial x^{\prime \sigma}}\left(\frac{\partial g_{\kappa \mu}}{\partial x^{\nu}}+\frac{\partial g_{\kappa \nu}}{\partial x^{\mu}}-\frac{\partial g_{\mu \nu}}{\partial x^{\kappa}}\right)=\frac{\partial x^{\kappa}}{\partial x^{\prime \alpha}} \frac{\partial x^{\mu}}{\partial x^{\prime \rho}} \frac{\partial x^{\nu}}{\partial x^{\prime \sigma}} \Gamma_{\kappa \mu \nu}
$$

sedangkan suku kedua dijabarkan lebih jauh lagi, didapat

$$
\begin{aligned}
\text { suku kedua }= & \left(\frac{\partial^{2} x^{\mu}}{\partial x^{\prime \sigma} \partial x^{\prime \alpha}} \frac{\partial x^{\nu}}{\partial x^{\prime \rho}}+\frac{\partial x^{\mu}}{\partial x^{\prime \alpha}} \frac{\partial^{2} x^{\nu}}{\partial x^{\prime \sigma} \partial x^{\prime \rho}}+\frac{\partial^{2} x^{\mu}}{\partial x^{\prime \rho} \partial x^{\prime \alpha}} \frac{\partial x^{\nu}}{\partial x^{\prime \sigma}}\right. \\
& \left.+\frac{\partial x^{\mu}}{\partial x^{\prime \alpha}} \frac{\partial^{2} x^{\nu}}{\partial x^{\prime \rho} \partial x^{\prime \sigma}}-\frac{\partial^{2} x^{\mu}}{\partial x^{\prime \alpha} \partial x^{\prime \rho}} \frac{\partial x^{\nu}}{\partial x^{\prime \sigma}}-\frac{\partial x^{\mu}}{\partial x^{\prime \rho}} \frac{\partial^{2} x^{\nu}}{\partial x^{\prime \alpha} \partial x^{\prime \sigma}}\right) g_{\mu \nu}
\end{aligned}
$$


komponen satu dengan terakhir saling cancel, dan komponen tiga dan kelima juga saling menghilangkan. Sehingga suku kedua ditulis

$$
\text { suku kedua }=\frac{\partial x^{\mu}}{\partial x^{\prime \alpha}} \frac{\partial^{2} x^{\nu}}{\partial x^{\prime \sigma} \partial x^{\prime \rho}} g_{\mu \nu}
$$

sehingga simbol christoffel jenis pertama bukanlah sebuah tensor

$$
\Gamma_{\alpha \rho \sigma}^{\prime}=\frac{\partial x^{\kappa}}{\partial x^{\prime \alpha}} \frac{\partial x^{\mu}}{\partial x^{\prime \rho}} \frac{\partial x^{\nu}}{\partial x^{\prime \sigma}} \Gamma_{\kappa \mu \nu}+\frac{\partial x^{\mu}}{\partial x^{\prime \alpha}} \frac{\partial^{2} x^{\nu}}{\partial x^{\prime \sigma} \partial x^{\prime \rho}} g_{\mu \nu}
$$

dengan memanfaatkan hasil transformasi pada jenis pertama, dapat kita lihat hasil transformasi pada jenis kedua

$$
\begin{aligned}
\Gamma_{\rho \sigma}^{\prime \lambda}=g^{\prime \lambda \alpha} \Gamma_{\alpha \rho \sigma}^{\prime} & =\frac{\partial x^{\prime \lambda}}{\partial x^{\beta}} \frac{\partial x^{\prime \alpha}}{\partial x^{\gamma}} g^{\beta \gamma}\left(\frac{\partial x^{\kappa}}{\partial x^{\prime \alpha}} \frac{\partial x^{\mu}}{\partial x^{\prime \rho}} \frac{\partial x^{\nu}}{\partial x^{\prime \sigma}} \Gamma_{\kappa \mu \nu}+\frac{\partial x^{\mu}}{\partial x^{\prime \alpha}} \frac{\partial^{2} x^{\nu}}{\partial x^{\prime \sigma} \partial x^{\prime \rho}} g_{\mu \nu}\right) \\
& =\frac{\partial x^{\prime \lambda}}{\partial x^{\beta}} \delta_{\gamma}^{\kappa} g^{\beta \gamma} \frac{\partial x^{\mu}}{\partial x^{\prime \rho}} \frac{\partial x^{\nu}}{\partial x^{\prime \sigma}} \Gamma_{\kappa \mu \nu}+\frac{\partial x^{\prime \lambda}}{\partial x^{\beta}} \delta_{\gamma}^{\mu} g^{\beta \gamma} \frac{\partial^{2} x^{\nu}}{\partial x^{\prime \sigma} \partial x^{\prime \rho}} g_{\mu \nu}
\end{aligned}
$$

didapat $^{18}$

$$
\Gamma_{\rho \sigma}^{\prime \lambda}=\frac{\partial x^{\prime \lambda}}{\partial x^{\beta}} \frac{\partial x^{\mu}}{\partial x^{\prime \rho}} \frac{\partial x^{\nu}}{\partial x^{\prime \sigma}} \Gamma_{\mu \nu}^{\beta}+\frac{\partial x^{\prime \lambda}}{\partial x^{\beta}} \frac{\partial^{2} x^{\beta}}{\partial x^{\prime \sigma} \partial x^{\prime \rho}}
$$

Hasil (5.11) dan (5.13) menyatakan bahwa simbol Christoffel bukanlah tensor, dikarenakan suku keduanya.

Beberapa properti matematis lainnya dapat dibentuk dari simbol Christoffel. Simbol Christoffel jenis kedua dengan dua index yang dikontraksi dapat ditulis

$$
\Gamma_{\rho \mu}^{\mu}=g^{\mu \alpha} \Gamma_{\alpha \rho \mu}=\frac{1}{2} g^{\mu \alpha} \frac{\partial g_{\mu \alpha}}{\partial x^{\rho}}+\frac{1}{2} g^{\mu \alpha}\left(\frac{\partial g_{\alpha \rho}}{\partial x^{\mu}}-\frac{\partial g_{\rho \mu}}{\partial x^{\alpha}}\right)=\frac{1}{2} g^{\mu \alpha} \frac{\partial g_{\mu \alpha}}{\partial x^{\rho}}
$$

Persamaan diatas dapat dibentuk dengan determinan $g$ dan tensor metrik $g_{\mu \nu}$. Pertamatama ${ }^{19}$ adjoint dari $g_{\mu \nu}$,

$$
\operatorname{adj}\left(g_{\mu \nu}\right)=\Delta^{\mu \nu}=g g^{\mu \nu}
$$

Dari sini dapat dibentuk ${ }^{20}$

$$
d g=g g^{\mu \nu} d g_{\mu \nu}
$$

Kedua, dengan differensiasi kuantitas $g^{\mu \nu} g_{\mu \nu}$ menghasilkan ${ }^{21}$

$$
d\left(g^{\mu \nu} g_{\mu \nu}\right)=g_{\mu \nu} d\left(g^{\mu \nu}\right)+g^{\mu \nu} d\left(g_{\mu \nu}\right)=0
$$

sehingga $g^{\mu \nu} d g_{\mu \nu}=-g_{\mu \nu} d g^{\mu \nu}$, maka pers. (5.16) dapat ditulis

$$
d g=-g g_{\mu \nu} d\left(g^{\mu \nu}\right)
$$

Selanjutnya, subtitusi (5.16) ke (5.14) ditulis bentuk penulisan baru dengan ${ }^{22}$

$$
\Gamma_{\rho \mu}^{\mu}=\frac{1}{2 g} \frac{\partial g}{\partial x^{\rho}}=\frac{1}{\sqrt{-g}} \frac{\partial \sqrt{-g}}{\partial x^{\rho}}
$$

Salah satu properti lainnya adalah jika kita menghitung ${ }^{23}$

$$
g^{\rho \sigma} \Gamma_{\rho \sigma}^{\mu}=\frac{1}{2} g^{\rho \sigma} g^{\mu \sigma}\left(\frac{\partial g_{\alpha \rho}}{\partial x^{\sigma}}+\frac{\partial g_{\alpha \sigma}}{\partial x^{\rho}}-\frac{\partial g_{\rho \sigma}}{\partial x^{\alpha}}\right)=g^{\rho \sigma} g^{\mu \sigma}\left(\frac{\partial g_{\alpha \rho}}{\partial x^{\sigma}}-\frac{1}{2} \frac{\partial g_{\rho \sigma}}{\partial x^{\alpha}}\right)
$$

19 determinan dari matriks $g_{\mu \nu}$,

$$
\operatorname{det}\left(g_{\mu \nu}\right)=g
$$

. Dan invers dari matriks $g_{\mu \nu}$

$$
\left[g_{\mu \nu}\right]^{-1}=g^{\mu \nu}
$$

20 perhatikan bahwa

$$
g=\Delta^{\mu \nu} g_{\mu \nu}
$$

${ }^{21}$ dimana $g^{\mu \nu} g_{\mu \nu}=\delta_{\mu}^{\mu}=4$

22 nilai $\sqrt{-g}$ memberikan nilai non-kompleks

23 kalikan dahulu dengan ketiga komponen, maka intuisi pertukaran indeks akan terlihat 
menggunakan hubungan (5.17), maka suku pertama menjadi

$$
g^{\rho \sigma} g^{\mu \sigma} \frac{\partial g_{\alpha \rho}}{\partial x^{\sigma}}=-g^{\rho \sigma} g_{\alpha \rho} \frac{\partial g^{\mu \sigma}}{\partial x^{\sigma}}=-\delta_{\alpha}^{\sigma} \frac{\partial g^{\mu \sigma}}{\partial x^{\sigma}}=-\frac{\partial g^{\mu \sigma}}{\partial x^{\alpha}}
$$

dan suku kedua menggunakan hasil (5.16) dan (5.19), maka didapat

$$
\frac{1}{2} g^{\mu \sigma} g^{\rho \sigma} \frac{\partial g_{\rho \sigma}}{\partial x^{\alpha}}=g^{\mu \sigma} \Gamma_{\alpha \rho}^{\rho}=g^{\mu \sigma} \frac{1}{\sqrt{-g}} \frac{\partial \sqrt{-g}}{\partial x^{\alpha}}
$$

disimpulkan (5.19) menjadi

$$
g^{\rho \sigma} \Gamma_{\rho \sigma}^{\mu}=-\frac{\partial g^{\mu \sigma}}{\partial x^{\alpha}}-g^{\mu \sigma} \frac{1}{\sqrt{-g}} \frac{\partial \sqrt{-g}}{\partial x^{\alpha}}=-\frac{1}{\sqrt{-g}} \frac{\partial\left(g^{\mu \sigma} \sqrt{-g}\right)}{\partial x^{\alpha}}
$$

\subsection{Covariant Derivative}

Pada bab 1.3 kita lihat bahwa derivatif dari fungsi skalar yang merupakan komponen dari vektor kontravarian merupakan sebuah tensor (rank-1), yang ditunjukkan dari transformasinya. Pada kasus derivatif dari tensor, kita lihat sebagai perbedaan tensor pada dua titik ruangwaktu yang berbeda secara infinitesimal. Namun, setiap titik pada ruangwaktu bertransformasi dengan cara yang berbeda, yang ditunjukkan oleh gradien transformasi merupakan fungsi dari koordinat itu sendiri. Maka apakah derivatif dari tensor dapat dilihat sebagai tensor? Dimana derivatif vektor kontravarian

$\frac{\partial V^{\mu}}{\partial x^{\alpha}}=\frac{\partial}{\partial x^{\alpha}}\left(\frac{\partial x^{\mu}}{\partial x^{\prime \nu}} V^{\prime \nu}\right)=\frac{\partial x^{\prime \rho}}{\partial x^{\alpha}} \frac{\partial}{\partial x^{\prime \rho}}\left(\frac{\partial x^{\mu}}{\partial x^{\prime \nu}} V^{\prime \nu}\right)=\frac{\partial x^{\mu}}{\partial x^{\prime \nu}} \frac{\partial x^{\prime \rho}}{\partial x^{\alpha}} \frac{\partial V^{\prime \nu}}{\partial x^{\prime \rho}}+\frac{\partial^{2} x^{\mu}}{\partial x^{\prime \rho} \partial x^{\prime \nu}} \frac{\partial x^{\prime \rho}}{\partial x^{\alpha}} V^{\prime \nu}$

Terlihat bahwa suku kedua membuat derivatif dari vektor (tensor rank-1) tidak berperilaku sebagai tensor. Dari hal ini, kita membutuhkan operasi derivatif yang tidak menghilangkan sifat tensor. Ini dapat kita bentuk dari persamaan derivatif biasa diatas, dimana suku keduanya dapat di subtitusi dengan suku kedua dari pers.(5.13) dimana

$$
\frac{\partial^{2} x^{\mu}}{\partial x^{\prime \nu} \partial x^{\prime \rho}}=\Gamma_{\rho \nu}^{\prime \lambda} \frac{\partial x^{\mu}}{\partial x^{\prime \lambda}}-\frac{\partial x^{\kappa}}{\partial x^{\prime \rho}} \frac{\partial x^{\lambda}}{\partial x^{\prime \nu}} \Gamma_{\kappa \lambda}^{\mu}
$$

Hasil subtitusi ini memberikan ${ }^{24}$

$$
\frac{\partial V^{\mu}}{\partial x^{\alpha}}+\Gamma_{\alpha \lambda}^{\mu} V^{\lambda}=\frac{\partial x^{\mu}}{\partial x^{\prime \lambda}} \frac{\partial x^{\rho}}{\partial x^{\alpha}}\left(\frac{\partial V^{\prime \lambda}}{\partial x^{\prime \rho}}+\Gamma_{\rho \nu}^{\prime \lambda} V^{\prime \nu}\right)
$$

Hasil (5.25) memberikan transformasi layaknya suatu tensor. Sehingga kita definisikan bentuk derivatif baru yang disebut sebagai covariant derivative ${ }^{25}$, yakni derivatif yang menjaga nilai tensor. Dimana

$$
\nabla_{\alpha} V^{\mu}=\frac{\partial V^{\mu}}{\partial x^{\alpha}}+\Gamma_{\alpha \lambda}^{\mu} V^{\lambda}
$$

Untuk vektor kovarian, covariant derivative-nya diberikan dengan (Lihat Lampiran 7)

$$
\nabla_{\alpha} V_{\beta}=\frac{\partial V_{\beta}}{\partial x^{\alpha}}-\Gamma_{\alpha \beta}^{\lambda} V_{\lambda}
$$

dan untuk tensor rank-2, covariant derivativenya diberikan dengan (Lihat Lampiran 7)

$$
\begin{aligned}
\nabla_{\gamma} T^{\alpha \beta} & =\frac{\partial T^{\alpha \beta}}{\partial x^{\gamma}}+\Gamma_{\gamma \lambda}^{\alpha} T^{\lambda \beta}+\Gamma^{\beta} \gamma \lambda T^{\alpha \lambda} \\
\nabla_{\gamma} T_{\beta}^{\alpha} & =\frac{\partial T_{\beta}^{\alpha}}{\partial x^{\gamma}}+\Gamma_{\gamma \lambda}^{\alpha} T_{\beta}^{\lambda}-\Gamma_{\gamma \beta}^{\lambda} T_{\lambda}^{\alpha} \\
\nabla_{\gamma} T_{\alpha \beta} & =\frac{\partial T_{\alpha \beta}}{\partial x^{\gamma}}-\Gamma_{\gamma \alpha}^{\lambda} T_{\lambda \beta}-\Gamma_{\gamma \beta}^{\lambda} T_{\alpha \lambda}
\end{aligned}
$$

Beberapa sifat covariant derivative, antara lain 
1. Covariant derivative dari kombinasi linear dengan koefisien konstan, sama dengan kombinasi linear dari covariant derivative tiap tensor

2. Covariant derivative dari produk tensor mengikuti aturan rantai dari derivatif biasa, dimana

$$
\nabla_{\alpha}\left(A^{\beta} T_{\gamma \sigma}\right)=\nabla_{\alpha}\left(A^{\beta}\right) T_{\gamma \sigma}+A^{\beta} \nabla_{\alpha}\left(T_{\gamma \sigma}\right)
$$

3. Covariant derivative dari tensor metrik bernilai nol (Lihat Lampiran 8)

$$
\nabla_{\alpha} g_{\mu \nu}=0 ; \quad \nabla_{\alpha} g^{\mu \nu}=0
$$

4. Covariant derivative dari kronecker delta tensor bernilai nol

$$
\nabla_{\alpha} \delta_{\nu}^{\mu}=0
$$

terlihat

$$
\nabla_{\alpha} \delta_{\nu}^{\mu}=\delta_{\nu}^{\mu},_{\alpha}+\Gamma_{\alpha \rho}^{\mu} \delta_{\nu}^{\rho}-\Gamma_{\alpha \nu}^{\rho} \delta_{\rho}^{\mu}=\Gamma_{\alpha \nu}^{\mu}-\Gamma_{\alpha \nu}^{\mu}=0
$$

5. Covariant derivative dari fungsi skalar bernilai derivatif parsial dari fungsi itu sendiri

$$
\nabla_{\alpha} \phi(x)=\phi(x), \alpha
$$

Dari sifat ke-3, terlihat proses menaikkan dan menurunkan operator dengan tensor metrik tidak mempengaruhi covariant derivative, dimana

$$
\nabla_{\alpha} V^{\beta}=\nabla_{\alpha}\left(g^{\beta \gamma} V_{\gamma}\right)=g^{\beta \gamma} \nabla_{\alpha} V_{\gamma}
$$

\section{Geodesik}

Geodesik adalah jarak terpendek antar dua titik, dimana jarak ditulis

$$
d s^{2}=g_{\mu \nu} d x^{\mu} d x^{\nu}
$$

Kita menggunakan parameter khusus ${ }^{26}$ untuk mengevaluasi tiap kurva koordinat, yakni $\lambda{ }^{26}$ disebut sebagai affine parameter sebagai paramater bebas, dengan $x^{\mu}(\lambda)$. Sehingga persamaan (6.1) ditulis

$$
d s^{2}=g_{\mu \nu} \dot{x}^{\mu} \dot{x}^{\nu} d \lambda^{2}=0
$$

Dikarenakan tujuannya adalah meminimalisasi nilai $d s^{2}$, sehingga $\delta\left(d s^{2}\right)=0$, maka bagian kiri dapat kita lihat sebagai lagrangian untuk geodesik

$$
L=L\left(x^{\mu}, \dot{x}^{\mu}\right)=g_{\mu \nu} \dot{x}^{\mu} \dot{x}^{\nu}
$$

Maka kita evaluasi persamaan euler-lagrange-nya,

$$
\frac{\partial L}{\partial x^{\mu}}=g_{\alpha \beta, \mu} \dot{x}^{\alpha} \dot{x}^{\beta}
$$

dan

$$
\frac{\partial L}{\partial \dot{x}^{\mu}}=g_{\alpha \beta}\left(\frac{\partial \dot{x}^{\alpha}}{\partial \dot{x}^{\mu}}\right) \dot{x}^{\beta}+g_{\alpha \beta}\left(\frac{\partial \dot{x}^{\beta}}{\partial \dot{x}^{\mu}}\right) \dot{x}^{\alpha}=g_{\mu \beta} \dot{x}^{\beta}+g_{\alpha \mu} \dot{x}^{\alpha}=2 g_{\mu \beta} \dot{x}^{\beta}
$$

Ialu

$$
\frac{d}{d \lambda} \frac{\partial L}{\partial \dot{x}^{\mu}}=2 \frac{\partial g_{\mu \beta}}{\partial \lambda} \dot{x}^{\beta}+2 g_{\mu \beta} \ddot{x}^{\beta}=2 g_{\mu \beta, \alpha} \dot{x}^{\alpha} \dot{x}^{\beta}+2 g_{\mu \beta} \ddot{x}^{\beta}
$$


Maka total persamaan euler-lagrange didapat

$$
\begin{aligned}
g_{\alpha \beta, \mu} \dot{x}^{\alpha} \dot{x}^{\beta}-2 g_{\mu \beta, \alpha} \dot{x}^{\alpha} \dot{x}^{\beta}-2 g_{\mu \beta} \ddot{x}^{\beta} & =0 \quad \times\left(-\frac{1}{2} g^{\rho \mu}\right) \\
\delta_{\beta}^{\rho} \ddot{x}^{\beta}+g^{\rho \mu} g_{\mu \beta, \alpha} \dot{x}^{\alpha} \dot{x}^{\beta}-\frac{1}{2} g^{\rho \mu} g_{\alpha \beta, \mu} \dot{x}^{\alpha} \dot{x}^{\beta} & =0 \\
\ddot{x}^{\rho}+\frac{1}{2} g^{\rho \mu}\left(g_{\mu \alpha, \beta}+g_{\mu \beta, \alpha}-g_{\alpha \beta, \mu}\right) \dot{x}^{\alpha} \dot{x}^{\beta} & =0
\end{aligned}
$$

sehingga didapat persamaan geodesik

$$
\ddot{x}^{\rho}+\Gamma_{\alpha \beta}^{\rho} \dot{x}^{\alpha} \dot{x}^{\beta}=0
$$

Lihat Lampiran 9, untuk lintasan geodesik pada ruang datar menggunakan koordinat polar.

\subsection{Parallel Transport}

Pada ruang datar, transport (perpindahan posisi) suatu vektor secara parallel, dimana komponen vektornya tidak mengalami perubahan, tidak bergantung dengan lintasan bagaimana vektor tersebut dipindahkan, seperti yang ditunjukkan oleh gambar 4. Namun pada ruang lengkung, lintasan sangat mempengaruhi bagaimana hasil akhir vektor. Misalkan yang ditunjukkan oleh gambar 5, vektor mula-mula berada di posisi a, namun kita pindahkan vektor tersebut dengan lintasan yang berbeda, yakni pertama lintasan a-c, kedua lintasan a-b-c. Kita lihat bahwa pada akhir lintasan (titik c), arah vektor berbeda dengan berbedanya lintasan. Sehingga pada ruang lengkung ini, kita harus mencari lintasan unik yang tetap menjaga paralellitas vektor tersebut.

Pertama-tama, agar vektor yang ditransport bersifat paralel, komponen vektornya tidak boleh berubah, sehingga harus dipenuhi

$$
\frac{d V^{\mu}}{d \lambda}=0
$$

Salah satu aspek penting dalam menjaga paralellitas dalam ruang lengkung adalah menjaga vektor tangent pada setiap lintasan, maknannya, lintasan yang dipilih untuk parallel transport adalah lintasan yang setiap titiknya memiliki vektor tangent yang paralel terhadap vektor yang ingin ditransport itu sendiri. Sehingga, pers.(6.8)

$$
\frac{\partial x^{\alpha}}{\partial \lambda} \nabla_{\alpha} V^{\mu}=\frac{\partial x^{\alpha}}{\partial \lambda}\left(\partial_{\alpha} V^{\mu}+\Gamma_{\alpha \kappa}^{\mu} V^{\kappa}\right)=0
$$

Vektor $V^{\mu}$ harus paralel dengan vektor tangent oleh lintasan parallel transportnya, sehingga

$$
V^{\mu}=\frac{d x^{\mu}}{d \lambda} \quad \text { tangent vector }
$$

Maka, didapat lintasan parallel transport adalah

$$
\frac{\partial x^{\alpha}}{\partial \lambda} \frac{\partial}{\partial x^{\alpha}} \frac{d x^{\mu}}{d \lambda}+\Gamma_{\alpha \kappa}^{\mu} \frac{\partial x^{\alpha}}{\partial \lambda} \frac{d x^{\kappa}}{d \lambda}=\frac{\partial^{2} x^{\mu}}{\partial \lambda^{2}}+\Gamma_{\alpha \kappa}^{\mu} \frac{\partial x^{\alpha}}{\partial \lambda} \frac{\partial x^{\kappa}}{\partial \lambda}=0
$$

Terlihat bahwa solusi parallel transport adalah lintasan geodesik dari sebuah ruang lengkung.

\section{Kelengkungan}

Bagaimana mendefinisikan suatu kelengkungan? Pada ruang lengkung bola, vektor dapat ditransportkan pada lintasan tertutup, namun hasil akhir vektor tidak sama dengan hasil awal vektor, seperti yang ditunjukkan oleh lintasan PNQRP pada gambar 6. Sehingga ruang lengkung merupakan suatu ruang yang lintasan tertutupnya tidak memberikan hasil

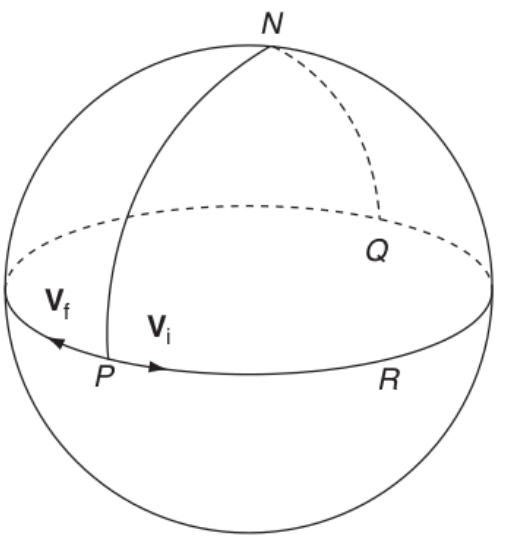

Gambar 6: Lintasan tertutup PNQRP

tidak memberikan hasil paralel

Gambar 4: Perpindahan vektor secara paralel tidak bergantung dengan lintasan pada ruang datar

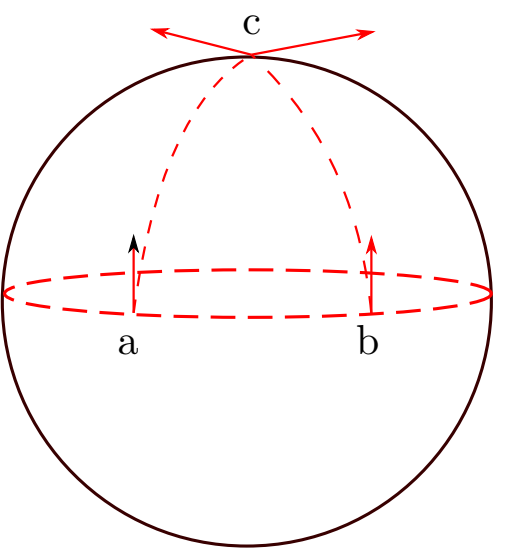

Gambar 5: Perpindahan vektor secara paralel pada ruang lengkung sangat bergantung dengan lintasan. Hasil akhir vektor di titik c berbeda pada lintasan $a-c$ dengan $a-b-c$. 
paralell, kecuali lintasan geodesiknya. Dari hal ini, tentu ruang silinder tidak termasuk ruang lengkung, karena silinder sini merupakan perluasan dari ruang datar. Dimana silinder dapat membentuk ruang datar jika di potong, berbeda dengan bola yang tidak akan dapat dibuat ruang datar walaupun dipotong atau dibelah.

Maka, jika vektor $V^{\alpha}$ dipindahkan pada lintasa tertutup, maka

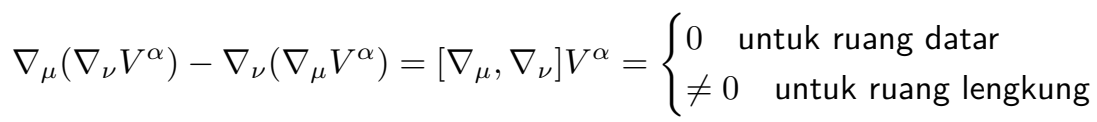

Differensiasi dua kali tensor dengan derivatif kovariant didapat ${ }^{27}$

$$
\begin{aligned}
\nabla_{\mu} \nabla_{\nu} V^{\alpha} & =\partial_{\mu}\left(\nabla_{\nu} V^{\alpha}\right)+\Gamma_{\mu \lambda}^{\alpha}\left(\nabla_{\nu} V^{\lambda}\right)-\Gamma_{\mu \nu}^{\lambda}\left(\nabla_{\lambda} V^{\alpha}\right) \\
& =\partial_{\mu}\left(\partial_{\nu} V^{\alpha}+\Gamma_{\nu \sigma}^{\alpha} V^{\sigma}\right)+\Gamma_{\mu \lambda}^{\alpha}\left(\partial_{\nu} V^{\lambda}+\Gamma_{\nu \sigma}^{\lambda} V^{\sigma}\right)-\Gamma_{\mu \nu}^{\lambda}\left(\partial_{\lambda} V^{\alpha}+\Gamma_{\lambda \sigma}^{\alpha} V^{\sigma}\right)
\end{aligned}
$$

maka, relasi komutatif ini didapat

$$
\left[\nabla_{\mu}, \nabla_{\nu}\right] V^{\alpha}=\left(\partial_{\mu} \Gamma_{\nu \sigma}^{\alpha}-\partial_{\nu} \Gamma_{\mu \sigma}^{\alpha}+\Gamma_{\mu \lambda}^{\alpha} \Gamma_{\nu \sigma}^{\lambda}-\Gamma_{\nu \lambda}^{\alpha} \Gamma_{\mu \sigma}^{\lambda}\right) V^{\sigma}
$$

dari (7.2), didefinisikan tensor kelengkungan Riemann

$$
R_{\sigma \mu \nu}^{\alpha} \equiv \partial_{\mu} \Gamma_{\nu \sigma}^{\alpha}-\partial_{\nu} \Gamma_{\mu \sigma}^{\alpha}+\Gamma_{\mu \lambda}^{\alpha} \Gamma_{\nu \sigma}^{\lambda}-\Gamma_{\nu \lambda}^{\alpha} \Gamma_{\mu \sigma}^{\lambda}
$$

Dimana pada ruang lengkung $R_{\sigma \mu \nu}^{\alpha} \neq 0$

\subsection{Properti tensor kelengkungan Riemann}

Sifat pertama adalah tidak semua komponen independen, dapat dilihat dari (7.3),

$$
R_{\sigma \mu \nu}^{\alpha}=-R_{\sigma \nu \mu}^{\alpha}
$$

Sifat simetri aljabar tensor Riemann lainnya dapat dilihat jika indeks-nya dapat di turunkan dengan tensor metrik,

$$
R_{\rho \sigma \mu \nu}=g_{\alpha \rho} R_{\sigma \mu \nu}^{\alpha}
$$

ini menghasilkan (Lihat Lampiran 10)

$$
R_{\rho \sigma \mu \nu}=\partial_{\mu} \partial_{\sigma} g_{\rho \nu}-\partial_{\mu} \partial_{\rho} g_{\nu \sigma}-\partial_{\nu} \partial_{\sigma} g_{\rho \mu}+\partial_{\nu} \partial_{\rho} g_{\mu \sigma}+\Gamma_{\mu \lambda}^{\alpha} \Gamma_{\nu \sigma}^{\lambda}-\Gamma_{\nu \lambda}^{\alpha} \Gamma_{\mu \sigma}^{\lambda}
$$

dari sini dapat kita lihat sifat simetri

$$
R_{\rho \sigma \mu \nu}=-R_{\sigma \rho \mu \nu} \quad \text { dan } \quad R_{\rho \sigma \mu \nu}=-R_{\rho \sigma \nu \mu}
$$

dan sumasih tiga permutasi indeks terakhir dapat dibuktikkan dengan mudah bahwa

$$
R_{\rho[\sigma \mu \nu]}=R_{\rho \sigma \mu \nu}+R_{\rho \mu \nu \sigma}+R_{\rho \nu \sigma \mu}=0
$$

\subsection{Tensor Ricci dan Tensor Einstein}

Dari tensor kelengkungan Riemann, kita dapat membentuk tensor Ricci, dengan mengkonstraksi 2 suku pada tensor kelengkungan Riemann, dimana

$$
R_{\mu \nu}=R_{\mu \alpha \nu}^{\alpha}=\Gamma_{\mu \nu, \alpha}^{\alpha}-\Gamma_{\alpha \mu, \nu}^{\alpha}+\Gamma_{\alpha \sigma}^{\alpha} \Gamma_{\mu \nu}^{\sigma}-\Gamma_{\mu \sigma}^{\alpha} \Gamma_{\alpha \mu}^{\sigma}
$$

dan dengan mengkonstraksikan kedua indeks tensor ricci, maka didapat

$$
R=g^{\mu \nu} R_{\mu \nu}
$$

Tensor kelengkungan skalar. Selanjutnya, Tensor Einstein didefinisikan

$$
G_{\mu \nu} \equiv R_{\mu \nu}-\frac{1}{2} g_{\mu \nu} R
$$

27 untuk suku kedua hanya perturakan indeks 


\section{Persamaan Medan Einstein}

\subsection{Persamaan medan Einstein dengan Geodesik}

Pada gravitasi klasik, kita ketahui bahwa

1. Distribusi materi pada ruang menghasilkan dan mempengaruhi medan gravitasi dengan $\nabla^{2} \Phi=4 \pi G \rho$

2. Medan gravitasi mengatur interaksi antar materi dengan $d^{2} \boldsymbol{r} / d t^{2}=g=-\nabla \Phi$

Kita ingin melihat bagaimana medan gravitasi dilihat sebagai kelengkungan ruangwaktu, dan kompatibel dengan relativitas khusus.

Pertama-tama, Geodesik ruang dengan affine paramaternya diambil adalah proper time $\lambda=\tau$, dimana

$$
\begin{aligned}
d \tau & =d s / c=\frac{1}{c} \sqrt{n_{\mu \nu} d x^{\mu} d x^{\nu}}=\sqrt{d t^{2}-\frac{d\left(x^{1}\right)^{2}}{c^{2}}-\frac{d\left(x^{2}\right)^{2}}{c^{2}}-\frac{d\left(x^{3}\right)^{2}}{c^{2}}} \\
& =\sqrt{1-\frac{1}{c^{2}}\left[\left(\frac{d x^{1}}{d t}\right)^{2}+\left(\frac{d x^{2}}{d t}\right)^{2}+\left(\frac{d x^{3}}{d t}\right)^{2}\right]} d t=\sqrt{1-\left(\frac{\boldsymbol{v}}{c}\right)^{2}} d t=\frac{d t}{\gamma}
\end{aligned}
$$

dan geodesiknya

$$
\frac{d^{2} x^{\mu}}{d \tau^{2}}+\Gamma_{\alpha \beta}^{\mu} \frac{d x^{\alpha}}{d \tau} \frac{d x^{\beta}}{d \tau}=0
$$

Selanjutnya, kita pertimbangkan batas newtonian, yakni:

1. kecepatan jauh lebih kecil dibanding kecepatan cahaya; $v \ll c$

2. Metrik statik terhadap waktu; $g_{\mu \nu, 0}=0$

3. Medan lemah (weak field); $g_{\mu \nu} \simeq \eta_{\mu \nu}+h_{\mu \nu}$ dengan $\left|h_{\mu \nu}\right| \ll 1$, dianggap sebagai pertubasi.

Dari kondisi (1), dilihat bahwa

$$
\tau \simeq t ; \quad \frac{d x^{0}}{d \tau} \simeq c ; \quad \frac{d x^{i}}{d \tau} \simeq v^{i} \ll c
$$

Maka, aproksimasi ini menghasilkan geodesik ${ }^{28}$

$$
\frac{d^{2} x^{\mu}}{d \tau^{2}}+\Gamma_{00}^{\mu}\left(\frac{d x^{0}}{d \tau}\right)=0
$$

dengan ${ }^{29}$

$$
\begin{aligned}
\Gamma_{00}^{\mu} & =\frac{1}{2} g^{\mu \nu}\left(2 g_{\nu 0,0}-g_{00, \nu}\right)=-\frac{1}{2} g^{\mu \nu} g_{00, \nu}=-\frac{1}{2}\left(\eta^{\mu \nu}-h^{\mu \nu}\right) \partial_{\nu}\left(\eta_{00}+h_{00}\right) \\
& =-\frac{1}{2} \eta^{\mu \nu} h_{00, v}+h^{\mu \nu} h_{00, \nu} \approx-\frac{1}{2} \eta^{\mu \nu} h_{00, \nu}
\end{aligned}
$$

28 suku $\frac{d x^{i}}{d \tau} \quad$ dapat diabaikan
karena $v \ll c$

${ }^{29}$ terapkan kondisi (2) dan (3)

Maka untuk $\mu=0^{30}$

$$
\frac{d^{2} t}{d \tau^{2}}=\frac{1}{2} \eta^{0 \nu} h_{00, \nu}\left(\frac{d t}{d \tau}\right)^{2}=0
$$

30 Turunan dua kali $t$ terhadap $\tau$ bernilai nol, karena hubungan linear keduanya

sedangkan untuk $\mu=i^{31}$

31 Kaitkan dengan percepatan gravitasi 


$$
\begin{aligned}
& \frac{d^{2} x^{i}}{d \tau^{2}}=\frac{1}{2} \eta^{i \nu} h_{00, \nu}\left(\frac{d t}{d \tau}\right)^{2} \times\left(\frac{d \tau}{d t}\right)^{2} \\
& \frac{d^{2} x^{i}}{d \tau^{2}}=\frac{1}{2} h_{00, \nu} \rightarrow \frac{d^{2} \boldsymbol{r}}{d t^{2}}=\frac{1}{2} \nabla h_{00}=-\nabla \Phi
\end{aligned}
$$

maka didapat

$$
g_{00}=\eta_{00}+h_{00}=-(1+2 \Phi)
$$

Dari pernyataan pertama gravitasi klasik, dimana $\nabla^{2} \Phi=4 \pi G \rho$, maka seharusnya terdapat hubungan

$$
\nabla^{2} g_{00} \propto T_{00}
$$

dimana $T_{\mu \nu}$ adalah tensor energi-momentum. Namun, kita ketahui bahwa turunan pertama covariant derivative $\nabla_{\alpha} g_{00}=0$, sehingga hubungan ini kurang tepat. Hubungan ini akan tepat jika menggunakan tensor Ricci, dimana dibentuk hubungan linear dengan tensor energi-momentum, sehingga

$$
R_{\mu \nu} \doteq \kappa T_{\mu \nu}
$$

Namun, kembali kita perhatikan dengan baik, bahwa dari teorema Noether mengenai konservativitas, maka nilai $\nabla_{\alpha} T_{\mu \nu}=0$, namun $\nabla_{\alpha} R_{\mu \nu} \neq 0$, sehingga agar suku ruas kiri terpenuhi hubungan ini, kita menggunakan Tensor Einstein, sehingga

$$
R_{\mu \nu}-\frac{1}{2} g_{\mu \nu} R=\kappa T_{\mu \nu}
$$

Sekarang kita akan mencari nilai konstanta $\kappa$. Pertama persamaan diatas dikontraksikan dengan $g^{\mu} \nu$. didapat

$$
R-\frac{1}{2} \cdot 4 \cdot R=\kappa T \rightarrow R=-\kappa T
$$

sehingga persamaan (8.8) menjadi

$$
R_{\mu \nu}+\frac{1}{2} g_{\mu \nu} \kappa T=\kappa T_{\mu \nu} \rightarrow R_{\mu \nu}=\kappa\left(T_{\mu \nu}-\frac{1}{2} g_{\mu \nu} T\right)
$$

Pada kasus non-relativistik nilai $T$ dapat digeneralisir menjadi ${ }^{32}$

$$
T=g^{\mu \nu} T_{\mu \nu} \approx \eta^{00} T_{00}=-T_{00}=-\rho
$$

maka

$$
R_{00}=\kappa\left(T_{00}-\frac{1}{2} \eta_{00} T\right)=\kappa\left(\rho-\frac{1}{2} \rho\right)=\frac{1}{2} \kappa \rho
$$

dikarenakan

$$
R_{00}=\Gamma_{00, \alpha}^{\alpha}-\Gamma_{0 \alpha, 0}^{\alpha}+\Gamma_{00}^{\alpha} \Gamma_{\alpha \beta}^{\beta}-\Gamma_{0 \beta}^{\alpha} \Gamma_{\alpha 0}^{\beta}
$$

Suku kedua ${ }^{33}$ bernilai nol dikarenakan metrik statik, suku ketiga dan keempat diaproksimasikan bernilai nol dikarenakan memiliki orde $\mathcal{O}\left(h^{2}\right)$, sehingga tersisa ${ }^{34}$

$$
\begin{aligned}
R_{00} & \approx \Gamma_{00, \alpha}^{\alpha}=\partial_{\alpha}\left(-\frac{1}{2} g^{\alpha \beta} g_{00, \beta}\right)=-\frac{1}{2} \partial_{\alpha}\left(g^{\alpha i} g_{00, i}\right) \\
& \approx-\frac{1}{2} \frac{\partial^{2} g_{00}}{\partial\left(x^{i}\right)^{2}}=-\frac{1}{2} \nabla^{2} g_{00}=\frac{1}{2} \kappa \rho
\end{aligned}
$$

dikarenakan $g_{00}=-(1+2 \Phi)$, maka didapat

$$
\nabla^{2} \Phi=\frac{\kappa}{2} \rho \rightarrow \frac{\kappa}{2} \rho=4 \pi G \rho \rightarrow \kappa=8 \pi G
$$

disimpulkan persamaan Medan Einstein adalah

$$
R_{\mu \nu}-\frac{1}{2} g_{\mu \nu} R=8 \pi G T_{\mu \nu}
$$




\subsection{Formulasi Lagrangian: Aksi Hilbert-Einstein}

Persamaan medan Einstein dapat diturunkan melalui prinsip aksi terkecil. Hilbert menurunkan persamaan ini, dengan menggunakan aksi yang disebut sebagai aksi Hilbert-Einstein. Pertama, integral volume- $4^{35}$ yang diperumum ditulis

$$
\text { integral volume-4 } \Rightarrow \int d^{4} x \sqrt{-g}
$$

Densitas lagrangian gravitasi haruslah lah skalar, dan terdapat komponen yang memiliki derivatif kedua. Tensor Riemann merupakan konstruksi dari derivatif kedua metrik, maka agar skalar terdapat beberapa pilihan lagrangian gravitasi antara lain

$$
\mathcal{L}_{g}=R, R^{2}, R_{\mu \nu} R^{\mu \nu}, R_{\mu}^{\alpha \beta \nu} R_{\alpha \beta \nu}^{\mu}, \ldots
$$

diambil skalar Ricci $\mathcal{L}_{g}=R$, sehingga

$$
\delta S_{E H}=\delta \int d^{4} x \sqrt{-g} R
$$

disebut sebagai aksi Hilbert-Einstein. Persamaan tersebut dapat dipecah menjadi

$$
\begin{aligned}
\delta S_{E H} & =\int d x^{4} \delta\left(\sqrt{-g} g^{a b} R_{a b}\right) \\
& =\int d^{4} x \sqrt{-g} g^{a b} \delta R_{a b}+\int d^{4} x \sqrt{-g} R_{a b} \delta g^{a b}+\int d^{4} x R \delta \sqrt{-g}
\end{aligned}
$$

Dievaluasi terlebih dahulu suku pertama, dicari nilai $\delta R_{a b}$, dikarenakan

$$
R_{a b}=R_{a c b}^{c}=\partial_{c} \Gamma_{a b}^{c}-\partial_{b} \Gamma_{a c}^{c}+\Gamma_{c d}^{c} \Gamma_{b a}^{d}-\Gamma_{b d}^{c} \Gamma_{a c}^{d}
$$

maka variasinya

$$
\begin{aligned}
\delta R_{a b} & =\partial_{c} \delta \Gamma_{a b}^{c}-\partial_{b} \delta \Gamma_{a c}^{c}+\Gamma_{b a}^{d} \delta \Gamma_{c d}^{c}+\Gamma_{c d}^{c} \delta \Gamma_{b a}^{d}-\Gamma_{a c}^{d} \delta \Gamma_{b d}^{c}-\Gamma_{b d}^{c} \delta \Gamma_{a c}^{d} \\
& =\left(\partial_{c} \delta \Gamma_{a b}^{c}+\Gamma_{c d}^{c} \delta \Gamma_{b a}^{d}-\Gamma_{a c}^{d} \delta \Gamma_{b d}^{c}-\Gamma_{b c}^{d} \delta \Gamma_{a d}^{c}\right)- \\
& \left(\partial_{b} \delta \Gamma_{a c}^{c}+\Gamma_{b d}^{c} \delta \Gamma_{a c}^{d}-\Gamma_{b a}^{d} \delta \Gamma_{c d}^{c}-\Gamma_{b c}^{d} \delta \Gamma_{a d}^{c}\right) \\
& =\nabla_{c} \delta \Gamma_{a b}^{c}-\nabla_{c} \delta \Gamma_{a c}^{c}
\end{aligned}
$$

Maka suku pertama variasi aksi

$$
\begin{aligned}
\delta S_{E H(1)} & =\int d^{4} x \sqrt{-g} g^{a b}\left(\nabla_{c} \delta \Gamma_{a b}^{c}-\nabla_{c} \delta \Gamma_{a c}^{c}\right) \\
& =\int d^{4} x \sqrt{-g}\left[\nabla_{c}\left(g^{a b} \delta \Gamma_{a b}^{c}\right)-\delta \Gamma_{a b}^{c} \nabla_{c} g^{a b}-\nabla_{b}\left(g^{a b} \delta \Gamma_{a c}^{c}\right)+\delta \Gamma_{a c}^{c} \nabla_{b} g^{a b}\right] \\
& =\int d^{4} x \sqrt{-g}\left[\nabla_{c}\left(g^{a b} \delta \Gamma_{a b}^{c}\right)-\nabla_{b}\left(g^{a b} \delta \Gamma_{a c}^{c}\right)\right] \\
& =\int d^{4} x \sqrt{-g} \nabla_{c}\left[g^{a b} \delta \Gamma_{a b}^{c}-g^{a c} \delta \Gamma_{a b}^{b}\right]
\end{aligned}
$$

menggunakan teorema stokes, didapat

$$
\delta S_{E H(1)}=\oint_{\text {permukaan }} d^{3} x \sqrt{-h} n_{c}\left[g^{a b} \delta \Gamma_{a b}^{c}-g^{a c} \delta \Gamma_{a b}^{b}\right]
$$

dimana $n_{c}$ adalah vektor normal dari permukaan ruang-4, dan tensor $h_{a b}$ adalah metrik yang diasosiakan dengan permukaan ruang-4, dimana

$$
h_{a} b=g_{a b}+n_{a} n_{b}
$$

35 Sebagai pengingat kembali, misal untuk koordinat bola,

$$
V=\int r^{2} \sin ^{2} \theta d t d r d \theta d \phi
$$

, dikarenakan

$g_{\mu \nu}=\left(\begin{array}{cccc}-1 & 0 & 0 & 0 \\ 0 & 1 & 0 & 0 \\ 0 & 0 & r^{2} & 0 \\ 0 & 0 & 0 & r^{2} \sin ^{2} \theta\end{array}\right)$

maka $\sqrt{-g}=r^{2} \sin \theta$, sehingga

$$
V=\int \sqrt{-g} d t d r d \theta d \phi
$$


integral permukaan pada ruang-4 ini bernilai nol, hal ini dikarenakan mengikuti teorema divergensi, yang mengatakan bahwa variasi di permukaan (tak berhingga) hilang, atau bernilai nol. Sehingga

$$
\delta S_{E H(1)}=0
$$

Sekarang untuk suku ketiga variasi aksi, dicari nilai $\delta \sqrt{-g}$. Variasi ini menghasilkan

$$
\delta \sqrt{-g}=-\frac{1}{2} \frac{1}{\sqrt{-g}} \delta g
$$

telah diketahui sebelumnya dari persamaan (5.16), didapat

$$
\delta \sqrt{-g}=-\frac{1}{2} \frac{1}{\sqrt{-g}} g g^{a b} d g_{a b}=\frac{1}{2} \sqrt{-g} g^{a b} d g_{a b}
$$

dan dari hubungan (5.17), didapat

$$
\delta \sqrt{-g}=-\frac{1}{2} \sqrt{-g} g_{a b} \delta g^{a b}
$$

Maka variasi aksi Hilber-Einstein pada (8.20) menjadi

$$
\begin{aligned}
\delta S_{E H} & =\int d^{4} x \sqrt{-g} R_{a b} \delta g^{a b}+\int d^{4} x R \delta \sqrt{-g} \\
& =\int d^{4} x \sqrt{-g}\left(R_{a b}-\frac{1}{2} g_{a b} R\right) \delta g^{a b}
\end{aligned}
$$

Dengan prinsip aksi terkecil $\delta S=0$, ini memberikan persamaan medan Einstein pada ruang vakum,

$$
R_{\mu \nu}-\frac{1}{2} g_{\mu \nu} R=0
$$

Agar memberikan persamaan medan einstein yang lengkap, maka diperlukan densitas lagrangian yang berkenaan dengan distribusi materi $\mathcal{L}_{M}\left[g_{\mu \nu}, \partial_{\alpha} g_{\mu \nu}\right]$, yang akan menghasilkan tensor energi-momentum. Dibentuk variasi aksi

$$
\delta S=\delta \int d^{4} x \sqrt{-g}\left(R-2 \kappa \mathcal{L}_{M}\right)
$$

dikarenakan suku pertama telah diselesaikan, maka variasi suku kedua memberikan

$$
\begin{aligned}
\delta S_{M} & =-2 \kappa \int d^{4} x \delta\left(\sqrt{-g} \mathcal{L}_{M}\right) \\
& =-2 \kappa \int d^{4} x\left\{\frac{\partial\left(\sqrt{-g} \mathcal{L}_{M}\right)}{\partial g^{\mu \nu}} \delta g^{\mu \nu}+\frac{\partial\left(\sqrt{-g} \mathcal{L}_{M}\right)}{\partial g_{, a}^{\mu \nu}} \delta g_{, a}^{\mu \nu}\right\} \\
& =-2 \kappa \int d^{4} x\left\{\frac{\partial\left(\sqrt{-g} \mathcal{L}_{M}\right)}{\partial g^{\mu \nu}} \delta g^{\mu \nu}+\left[\frac{\partial\left(\sqrt{-g} \mathcal{L}_{M}\right)}{\partial g_{, a}^{\mu \nu}} \delta g^{\mu \nu}\right]_{, a}-\left[\frac{\partial\left(\sqrt{-g} \mathcal{L}_{M}\right)}{\partial g_{, a}^{\mu \nu}}\right]_{, a} \delta g^{\mu \nu}\right\} \\
& =-2 \kappa \int d^{4} x\left\{\frac{\partial\left(\sqrt{-g} \mathcal{L}_{M}\right)}{\partial g^{\mu \nu}}-\left[\frac{\partial\left(\sqrt{-g} \mathcal{L}_{M}\right)}{\partial g_{, a}^{\mu \nu}}\right]_{, a}\right\} \delta g^{\mu \nu}
\end{aligned}
$$

dengan lagi-lagi pada integral permukaan $\delta g^{\mu \nu}=0$. Suku dalam kurung, dilihat sebagai persamaan euler-lagrange untuk tensor energi momentum, dimana

$$
\frac{1}{2} \sqrt{-g} T_{\mu \nu} \equiv \frac{\partial\left(\sqrt{-g} \mathcal{L}_{M}\right)}{\partial g^{\mu \nu}}-\left[\frac{\partial\left(\sqrt{-g} \mathcal{L}_{M}\right)}{\partial g_{, a}^{\mu \nu}}\right]_{, a}
$$

Sehingga

$$
\delta S_{M}=\int d^{4} x \sqrt{-g}\left(\kappa T_{\mu \nu}\right) \delta g^{\mu \nu}
$$

Maka prinsip aksi terkecil memberikan persamaan medan einstein

$$
R_{\mu \nu}-\frac{1}{2} g_{\mu \nu} R=\kappa T_{\mu \nu}
$$




\subsection{Solusi Schwarzchild dan Lubang Hitam}

Walaupun persamaan medan Einstein ini adalah persamaan differensial parsial non-linier, terdapat solusi eksak pada persamaan ini. Pada subbab ini akan di jelaskan solusi eksak tersebut. Solusi Schwarzschild adalah solusi persamaan medan Einstein paling mudah untuk di pelajari. Solusi ini mempunyai kondisi sederhana di antaranya adalah keadaan vakum, medan yang diam dan simetri bola. Dari kondisi tersebut dapat kita bentuk ansatz metrik,

$$
d s^{2}=-e^{2 \alpha} d t^{2}+e^{2 \beta} d r^{2}+r^{2} d \Omega^{2}
$$

di mana $\alpha$ dan $\beta$ adalah fungsi dari $r$ dan $d \Omega^{2}=d \theta^{2}+\sin ^{2} \theta d \phi^{2}$. Langkah pertama untuk mencari solusi ini adalah menentukan komponen simbol Christoffel yang tidak nol, yaitu

$$
\begin{array}{lll}
\Gamma_{t r}^{t}=\partial_{r} \alpha, & \Gamma_{t t}^{r}=e^{2(\alpha-\beta)} \partial_{r} \alpha, & \Gamma_{r r}^{r}=\partial_{r} \beta, \\
\Gamma_{\theta \theta}^{r}=-r e^{2 \beta}, & \Gamma_{\phi \phi}^{r}=-r e^{-2 \beta} \sin ^{2} \theta, & \Gamma_{r \theta}^{\theta}=\frac{1}{r}, \\
\Gamma_{\phi \phi}^{\theta}=-\sin \theta \cos \theta, & \Gamma_{r \phi}^{\phi}=\frac{1}{r}, & \Gamma_{\theta \phi}^{\phi}=\frac{\cos \theta}{\sin \theta},
\end{array}
$$

Setelah menentukan simbol Christoffel, langkah berikutnya adalah mencari tensor Ricci

$$
\begin{gathered}
R_{t t}=e^{2(\alpha-\beta)}\left[\partial_{r}^{2} \alpha+\left(\partial_{r} \alpha\right)^{2}-\partial_{r} \alpha \partial_{r} \beta+\frac{2}{r} \partial \alpha\right] \\
R_{r r}=-\partial_{r}^{2} \alpha-\left(\partial_{r} \alpha\right)^{2}+\partial_{r} \alpha \partial_{r} \beta+\frac{2}{r} \partial_{r} \beta \\
R_{\theta \theta}=e^{-2 \beta}\left[r\left(\partial_{r} \beta-\partial_{r} \alpha\right)\right]+1 \\
R_{\phi \phi}=\sin ^{2} \theta R_{\theta \theta}
\end{gathered}
$$

Kita ingin $R_{\mu \nu}=0$ karena keadaan vakum dan lakukan eliminasi pada persamaan (8.40) dan (8.41) kita dapatkan

$$
\alpha=-\beta
$$

manfaatkan hubungan ini untuk evaluasi persamaan (8.42) menjadi

$$
e^{2 \alpha}=1-\frac{R_{s}}{r},
$$

sehingga solusi metrik ini adalah

$$
d s^{2}-\left(1-\frac{R_{s}}{r}\right) d t^{2}+\left(1-\frac{R_{s}}{r}\right)^{-1} d r^{2}+r^{2} d \Omega^{2}
$$

dengan $R_{s}$ adalah konstanta.

salah satu cara yang kita lakukan adalah membuat $R_{s}$ menjadi radius Schwarzchild. Metrik Schwarzschild akan tereduksi menjadi medan lemah jika $r \gg 2 G M$, sehingga kita hanya identifikasi

$$
R_{s}=2 G M
$$

di mana $M$ bisa didefinisikan sebagai massa dari objek tersebut.

Sehingga solusi metrik tersebut menjadi

$$
d s^{2}=-\left(1-\frac{2 G M}{r}\right) d t^{2}+\left(1-\frac{2 G M}{r}\right)^{-1} d r^{2}+r^{2} d \Omega^{2}
$$

Pada persamaan (8.48), terdapat dua wilayah yang membuat solusi dari koefisien metrik tersebut tak berhingga, yaitu pada $r=0$ dan $r=2 G M$. Kita dapat menguji apakah kedua nilai tersebut menunjukkan adanya singularitas dengan besaran skalar. Ricci skalar adalah salah satu besaran skalar yang paling mudah, $R=R^{\mu \nu} R_{\mu \nu}$ atau bisa untuk orde 
yang lebih tinggi, misalnya $R^{\mu \nu \sigma \rho} R_{\mu \nu \sigma \rho}, R_{\mu \nu \rho \sigma} R^{\rho \sigma \lambda \tau} R_{\lambda \tau}^{\mu \nu}$ dan seterusnya. Pada metrik Schwarzchild, besaran skalar yang digunakan adalah skalar Kretschmann

$$
R^{\mu \nu \rho \sigma} R_{\mu \nu \rho \sigma}=\frac{48 G^{2} M^{2}}{r^{6}} .
$$

Hal ini bisa meyakinkan kita, ketika $r=0$ merepresentasikan nilai yang tak berhingga, hal ini dinamakan singularitas. Untuk $r=2 G M$ pada solusi Schwarzschild bukanlah singularitas yang nyata terjadi pada kelengkungan ruang dan waktu, melainkan singularitas yang muncul karena pemilihan sistem koordinat yang tidak baik atau secara umum disebut apparent singularity. Radius $r=2 G M$ pada metrik ini, dikenal sebagai event horizon. Event horizon adalah radius yang memisahkan antar ruang-waktu didalam $r<r_{E H}$ dan luarnya $r>r_{E H}$. pada $r<r_{E H}$, tidak ada materi apapun yang dapat keluar daripadanya, bahkan cahaya sekalipun. Bintang pada fase ini dinamakan lubang hitam. 


\section{Appendices}

\section{A Lampiran 1}

Pertama-tama

$$
\frac{\bar{\gamma}}{\gamma_{0}}=\frac{\sqrt{1-v_{0}^{2} / c^{2}}}{\sqrt{1-\bar{v}^{2} / c^{2}}}=\sqrt{\frac{\left(1+v_{0} / c\right)\left(1-v_{0} / c\right)}{(1+\bar{v} / c)(1-\bar{v} / c)}}
$$

bagian penyebut dapat dibentuk

$$
\begin{aligned}
(1+\bar{v} / c)(1-\bar{v} / c) & =\left(1+\frac{\left(v+v_{0}\right) / c}{1+v v_{0} / c^{2}}\right)\left(1-\frac{\left(v+v_{0}\right) / c}{1+v v_{0} / c^{2}}\right) \\
& =\left(1+v v_{0} / c^{2}\right)^{-2}\left[\left(1+v v_{0} / c^{2}\right)+\frac{v+v_{0}}{c}\right]\left[\left(1+v v_{0} / c^{2}\right)-\frac{v+v_{0}}{c}\right] \\
& =\left(1+v v_{0} / c^{2}\right)^{-2}\left[\left(1+\frac{v_{0}}{c}\right)\left(1+\frac{v}{c}\right)\right]\left[\left(1-\frac{v_{0}}{c}\right)\left(1-\frac{v}{c}\right)\right]
\end{aligned}
$$

dibagi dengan $\left(1+v_{0} / c\right)\left(1-v_{0} / c\right)$

$$
\begin{aligned}
\frac{(1+\bar{v} / c)(1-\bar{v} / c)}{\left(1+v_{0} / c\right)\left(1-v_{0} / c\right)} & =\left(1+v v_{0} / c^{2}\right)^{-2} \frac{\left(1+\frac{v_{0}}{c}\right)\left(1+\frac{v}{c}\right)}{\left(1+v_{0} / c\right)} \frac{\left(1-\frac{v_{0}}{c}\right)\left(1-\frac{v}{c}\right)}{\left(1-v_{0} / c\right)} \\
& =\left(1+v v_{0} / c^{2}\right)^{-2}\left(1+\frac{v}{c}\right)\left(1-\frac{v}{c}\right)=\left(1+v v_{0} / c^{2}\right)^{-2}\left(1-\frac{v^{2}}{c^{2}}\right)
\end{aligned}
$$

sehingga persamaan awal menjadi

$$
\frac{\bar{\gamma}}{\gamma_{0}}=\frac{\left(1+v v_{0} / c^{2}\right)}{\sqrt{1-v^{2} / c^{2}}}=\gamma\left(1+v v_{0} / c^{2}\right)
$$

\section{B Lampiran 2}

Ditulis ulang matriks transformasi lorentz dan tensor maxwell

$$
\Lambda=\left(\begin{array}{cccc}
\gamma & -\gamma v / c & 0 & 0 \\
-\gamma v / c & \gamma & 0 & 0 \\
0 & 0 & 1 & 0 \\
0 & 0 & 0 & 1
\end{array}\right) \quad F^{\mu \nu}=\left(\begin{array}{cccc}
0 & E_{x} / c & E_{y} / c & E_{z} / c \\
-E_{x} / c & 0 & B_{z} & -B_{y} \\
-E_{y} / c & -B_{z} & 0 & B_{x} \\
-E_{z} / c & B_{y} & -B_{x} & 0
\end{array}\right)
$$

Transformasi lorentz pada tensor maxwell

$$
F^{\prime \mu \nu}=\Lambda_{\alpha}^{\mu^{\prime}} \Lambda_{\beta}^{\nu^{\prime}} F^{\alpha \beta}
$$

pertama untuk $E_{x}^{\prime}$ dan $B_{x}^{\prime}$ dimana

$$
\begin{aligned}
\frac{E_{x}^{\prime}}{c}=F^{\prime 01} & =\Lambda_{\alpha}^{0} \Lambda_{\beta}^{1} F^{\alpha \beta}=\Lambda_{0}^{0} \Lambda_{1}^{1} F^{01}+\Lambda_{1}^{0} \Lambda_{0}^{1} F^{10} \\
& =\gamma^{2} \frac{E_{x}}{c}-\gamma^{2} \frac{v^{2}}{c^{2}} \frac{E_{x}}{c}=\gamma^{2}\left(1-\frac{v^{2}}{c^{2}}\right) \frac{E_{x}}{c}=\frac{E_{x}}{c}
\end{aligned}
$$

dan

$$
B_{x}^{\prime}=F^{\prime 23}=\Lambda_{\alpha}^{2} \Lambda_{\beta}^{3} F^{\alpha \beta}=\Lambda_{2}^{2} \Lambda_{3}^{3} F^{23}=B_{x}
$$

kedua untuk $E_{y}^{\prime}$ dan $B_{y}^{\prime}$ dimana

$$
\begin{aligned}
\frac{E_{y}^{\prime}}{c}=F^{\prime 02} & =\Lambda_{\alpha}^{0} \Lambda_{\beta}^{2} F^{\alpha \beta}=\Lambda_{0}^{0} \Lambda_{2}^{2} F^{02}+\Lambda_{1}^{0} \Lambda_{2}^{2} F^{12} \\
& =\gamma \cdot 1 \cdot \frac{E_{y}}{c}-\gamma \frac{v}{c} \cdot 1 \cdot B_{z}=\frac{\gamma}{c}\left(E_{y}-v B_{z}\right)
\end{aligned}
$$


dan

$$
\begin{aligned}
B_{y}^{\prime}=F^{\prime 31} & =\Lambda_{\alpha}^{3} \Lambda_{\beta}^{1} F^{\alpha \beta}=\Lambda_{3}^{3} \Lambda_{0}^{1} F^{30}+\Lambda_{3}^{3} \Lambda_{1}^{1} F^{31} \\
& =1 \cdot\left(-\gamma \frac{v}{c}\right) \cdot\left(-\frac{E_{z}}{c}\right)+1 \cdot \gamma B_{y}=\gamma\left(B_{y}+\frac{v}{c^{2}} E_{z}\right)
\end{aligned}
$$

kedua untuk $E_{z}^{\prime}$ dan $B_{z}^{\prime}$ dimana

$$
\begin{aligned}
\frac{E_{z}^{\prime}}{c}=F^{\prime 03} & =\Lambda_{\alpha}^{0} \Lambda_{\beta}^{3} F^{\alpha \beta}=\Lambda_{0}^{0} \Lambda_{3}^{3} F^{03}+\Lambda_{1}^{0} \Lambda_{3}^{3} F^{13} \\
& =\gamma \cdot 1 \cdot \frac{E_{z}}{c}-\gamma \frac{v}{c} \cdot 1 \cdot\left(-B_{y}\right)=\frac{\gamma}{c}\left(E_{z}+v B_{y}\right)
\end{aligned}
$$

dan

$$
\begin{aligned}
B_{z}^{\prime}=F^{\prime 2} & =\Lambda_{\alpha}^{1} \Lambda_{\beta}^{2} F^{\alpha \beta}=\Lambda_{0}^{1} \Lambda_{2}^{2} F^{02}+\Lambda_{1}^{1} \Lambda_{2}^{2} F^{12} \\
& =-\gamma \frac{v}{c} \cdot 1 \cdot \frac{E_{y}}{c}+\gamma \cdot 1 \cdot B_{z}=\gamma\left(B_{z}-\frac{v}{c^{2}} E_{y}\right)
\end{aligned}
$$

\section{Lampiran 3}

Ditulis ulang tensor maxwell

$$
F^{\mu \nu}=\left(\begin{array}{cccc}
0 & E_{x} / c & E_{y} / c & E_{z} / c \\
-E_{x} / c & 0 & B_{z} & -B_{y} \\
-E_{y} / c & -B_{z} & 0 & B_{x} \\
-E_{z} / c & B_{y} & -B_{x} & 0
\end{array}\right)
$$

Tensor dualnya dinyatakan

$$
\tilde{F}^{\mu \nu}=\frac{1}{2} \epsilon^{\mu \nu \alpha \beta} F^{\alpha \beta}
$$

pertama,

$$
\begin{aligned}
\tilde{F}^{0 i} & =\left\{\frac{1}{2} \epsilon^{01 \alpha \beta} F^{\alpha \beta}, \frac{1}{2} \epsilon^{02 \alpha \beta} F^{\alpha \beta}, \frac{1}{2} \epsilon^{03 \alpha \beta} F^{\alpha \beta}\right\} \\
& =\left\{\frac{1}{2}\left(\epsilon^{0123} F^{23}+\epsilon^{0132} F^{32}\right), \frac{1}{2}\left(\epsilon^{0213} F^{13}+\epsilon^{0231} F^{31}\right), \frac{1}{2}\left(\epsilon^{0312} F^{12}+\epsilon^{0321} F^{21}\right)\right\} \\
& =\left\{\frac{1}{2}\left(B_{x}+(-1)\left(-B_{x}\right)\right), \frac{1}{2}\left((-1)\left(-B_{y}\right)+B_{y}\right), \frac{1}{2}\left(B_{z}+(-1)\left(-B_{z}\right)\right)\right\} \\
& =\left\{B_{x}, B_{y}, B_{z}\right\}=-\tilde{F}^{i 0}
\end{aligned}
$$

lalu untuk komponen $\tilde{F}^{i j}=-\tilde{F}^{j i}$,

$$
\begin{aligned}
\tilde{F}^{12} & =\frac{1}{2}\left(\epsilon^{1203} F^{03}+\epsilon^{1230} F^{30}\right)=-\frac{E_{z}}{c} \\
\tilde{F}^{31} & =\frac{1}{2}\left(\epsilon^{3102} F^{02}+\epsilon^{3120} F^{20}\right)=-\frac{E_{y}}{c} \\
\tilde{F}^{23} & =\frac{1}{2}\left(\epsilon^{2301} F^{01}+\epsilon^{2310} F^{10}\right)=-\frac{E_{x}}{c}
\end{aligned}
$$

disimpulkan bahwa

$$
\tilde{F}^{\mu \nu}=\left(\begin{array}{cccc}
0 & B_{x} & B_{y} & B_{z} \\
-B_{x} & 0 & -E_{z} / c & E_{y} / c \\
-B_{y} & E_{z} / c & 0 & -E_{x} / c \\
-B_{z} & -E_{y} / c & E_{x} / c & 0
\end{array}\right)
$$




\section{Lampiran 4}

Dari persamaan (3.42) didapat

$$
\begin{aligned}
F_{\alpha \beta} F^{\alpha \beta}= & \eta^{\alpha \sigma} \eta^{\beta \lambda} F_{\alpha \beta} F_{\sigma \lambda} \\
& =\eta^{\alpha \sigma} \eta^{\beta \lambda}\left[\left(\partial_{\alpha} A_{\beta}-\partial_{\beta} A_{\alpha}\right)\left(\partial_{\sigma} A_{\lambda}-\partial_{\lambda} A_{\sigma}\right)\right] \\
& =\eta^{\alpha \sigma} \eta^{\beta \lambda}\left(\partial_{\alpha} A_{\beta} \partial_{\sigma} A_{\lambda}-\partial_{\alpha} A_{\beta} \partial_{\lambda} A_{\sigma}-\partial_{\beta} A_{\alpha} \partial_{\sigma} A_{\lambda}+\partial_{\beta} A_{\alpha} \partial_{\lambda} A_{\sigma}\right)
\end{aligned}
$$

suku kedua dapat ditulis

$$
\eta^{\alpha \sigma} \eta^{\beta \lambda} \partial_{\alpha} A_{\beta} \partial_{\lambda} A_{\sigma}=\eta^{\beta \lambda} \eta^{\alpha \sigma} \partial_{\beta} A_{\alpha} \partial_{\sigma} A_{\lambda}
$$

dan suku keempat ditulis

$$
\eta^{\alpha \sigma} \eta^{\beta \lambda} \partial_{\beta} A_{\alpha} \partial_{\lambda} A_{\sigma}=\eta^{\beta \lambda} \eta^{\alpha \sigma} \partial_{\alpha} A_{\beta} \partial_{\sigma} A_{\lambda}
$$

sehingga

$$
F_{\alpha \beta} F^{\alpha \beta}=2 \eta^{\alpha \sigma} \eta^{\beta \lambda}\left(\partial_{\alpha} A_{\beta} \partial_{\sigma} A_{\lambda}-\partial_{\beta} A_{\alpha} \partial_{\sigma} A_{\lambda}\right)
$$

Maka

$$
\begin{aligned}
\frac{\partial}{\partial\left(\partial_{\nu} A_{\mu}\right)}\left(F_{\alpha \beta} F^{\alpha \beta}\right) & =2 \eta^{\alpha \sigma} \eta^{\beta \lambda}\left[\left(\frac{\partial\left(\partial_{\alpha} A_{\beta}\right)}{\partial\left(\partial_{\nu} A_{\mu}\right)} \partial_{\sigma} A_{\lambda}+\partial_{\alpha} A_{\beta} \frac{\partial\left(\partial_{\sigma} A_{\lambda}\right)}{\partial\left(\partial_{\nu} A_{\mu}\right)}\right)-\left(\frac{\partial\left(\partial_{\beta} A_{\alpha}\right)}{\partial\left(\partial_{\nu} A_{\mu}\right)} \partial_{\sigma} A_{\lambda}+\partial_{\beta} A_{\alpha} \frac{\partial\left(\partial_{\sigma} A_{\lambda}\right)}{\partial\left(\partial_{\nu} A_{\mu}\right)}\right)\right] \\
& =2 \eta^{\alpha \sigma} \eta^{\beta \lambda}\left[\left(\delta_{\nu}^{\alpha} \delta_{\mu}^{\beta} \partial_{\sigma} A_{\lambda}+\delta_{\nu}^{\sigma} \delta_{\mu}^{\lambda} \partial_{\alpha} A_{\beta}\right)-\left(\delta_{\nu}^{\beta} \delta_{\mu}^{\alpha} \partial_{\sigma} A_{\lambda}+\delta_{\nu}^{\sigma} \delta_{\mu}^{\lambda} \partial_{\beta} A_{\alpha}\right)\right] \\
& =2\left[\left(\eta^{\nu \sigma} \eta^{\mu \lambda} \partial_{\sigma} A_{\lambda}+\eta^{\alpha \nu} \eta^{\beta \mu} \partial_{\alpha} A_{\beta}\right)-\left(\eta^{\mu \sigma} \eta^{\nu \lambda} \partial_{\sigma} A_{\lambda}+\eta^{\alpha \nu} \eta^{\beta \mu} \partial_{\beta} A_{\alpha}\right)\right] \\
& =2\left[\left(\partial^{\nu} A^{\mu}+\partial^{\nu} A^{\mu}\right)-\left(\partial^{\mu} A^{\nu}+\partial^{\mu} A^{\nu}\right)\right]=4\left(\partial^{\nu} A^{\mu}-\partial^{\mu} A^{\nu}\right)=4 F^{\nu \mu}
\end{aligned}
$$

Sehingga

$$
-\frac{1}{4} \frac{\partial}{\partial\left(\partial_{\nu} A_{\mu}\right)}\left(F_{\alpha \beta} F^{\alpha \beta}\right)=-F^{\nu \mu}
$$

disimpulkan dari persamaan euler-lagrange (3.39) dan hasil (3.40) didapat

$$
\mu_{0} J^{\mu}+\partial_{\nu} F^{\nu \mu}=0 \quad \text { dan } \quad \partial_{\nu} F^{\nu \mu}=-\mu_{0} J^{\mu}
$$

\section{E Lampiran 5}

persamaan (3.45) dapat dibentuk

$$
2\left(\delta F_{\mu \nu}\right) F^{\mu \nu}=2 F^{\mu \nu}\left[\delta\left(\partial_{\mu} A_{\nu}\right)-\delta\left(\partial_{\nu} A_{\mu}\right)\right]=2 F^{\mu \nu} \partial_{\mu}\left(\delta A_{\nu}\right)-2 F^{\mu \nu} \partial_{\nu}\left(\delta A_{\mu}\right)
$$

subtitusi ini ke persamaan (3.44) didapat

$$
\delta S=-\frac{1}{2} \int d^{4} x\left\{F^{\mu \nu} \partial_{\mu}\left(\delta A_{\nu}\right)-F^{\mu \nu} \partial_{\nu}\left(\delta A_{\mu}\right)\right\}+\text { suku arus }
$$

suku pertama dan kedua dapat dibentuk

$$
F^{\mu \nu} \partial_{\mu}\left(\delta A_{\nu}\right)=\partial_{\mu}\left[F^{\mu \nu} \delta A_{\nu}\right]-\partial_{\mu}\left[F^{\mu \nu}\right] \delta A_{\nu} \quad \text { dan } \quad \partial_{\nu}\left[F^{\mu \nu} \delta A_{\mu}\right]-\partial_{\nu}\left[F^{\mu \nu}\right] \delta A_{\mu}
$$

dengan kondisi batas, maka variasi aksi menjadi

$$
\delta S=\frac{1}{2} \int d^{4} x\left\{\left(\partial_{\mu} F^{\mu \nu}\right) \delta A_{\nu}-\left(\partial_{\nu} F^{\mu \nu}\right) \delta A_{\mu}\right\}+\text { suku arus }
$$

untuk suku pertama, dapat dipertukarkan indeks $\mu \leftrightarrow \nu$, dimana

$$
\left(\partial_{\mu} F^{\mu \nu}\right) \delta A_{\nu}=\left(\partial_{\nu} F^{\nu \mu}\right) \delta A_{\mu}=-\left(\partial_{\nu} F^{\mu \nu}\right) \delta A_{\mu}
$$

sehingga

$$
\delta S=\int d^{4} x\left\{-\left(\partial_{\nu} F^{\mu \nu}\right)+\mu_{0} J^{\mu}\right\} \delta A_{\mu}
$$

dengan prinsip aksi terkecil $\delta s=0$, maka

$$
\partial_{\nu} F^{\nu \mu}=-\mu_{0} J^{\mu}
$$




\section{F Lampiran 6}

Ini dengan sedikit penjabaran, didapat

$$
\begin{aligned}
F_{\mu \nu} \phi & =\frac{1}{i g}\left[D_{\mu}, D_{\nu}\right] \phi=\left[\left(\partial_{\mu}+i g A_{\mu}\right)\left(\partial_{\nu}+i g A_{\nu}\right) \phi-\left(\partial_{\nu}+i g A_{\nu}\right)\left(\partial_{\mu}+i g A_{\mu}\right) \phi\right] \\
& =\frac{1}{i g}\left[\partial_{\mu} \partial_{\nu} \phi+i g \partial_{\mu}\left(A_{\nu} \phi\right)+i g A_{\mu} \partial_{\nu} \phi-q^{2} A_{\mu} A_{\nu} \phi-\partial_{\nu} \partial_{\mu} \phi-i q \partial_{\nu}\left(A_{\mu} \phi\right)-i q A_{\nu} \partial_{\mu} \phi+q^{2} A_{\nu} A_{\mu} \phi\right] \\
& =\left(\partial_{\mu} A_{\nu}\right) \phi+A_{\nu} \partial_{\mu} \phi+A_{\mu} \partial_{\nu} \phi-\left(\partial_{\nu} A_{\mu}\right) \phi-A_{\mu} \partial_{\nu} \phi-A_{\nu} \partial_{\mu} \phi+i g\left(A_{\mu} A_{\nu}-A_{\nu} A_{\mu}\right) \phi
\end{aligned}
$$

sehingga

$$
F_{\mu \nu}=\partial_{\mu} A_{\nu}-\partial_{\nu} A_{\mu}+i g\left[A_{\mu}, A_{\nu}\right]
$$

\section{G Lampiran 7}

Transformasi vektor kovarian ditulis

$$
V_{\mu}^{\prime}=\frac{\partial x^{\alpha}}{\partial x^{\prime \mu}} V_{\alpha}
$$

memiliki derivatif

$$
\frac{\partial V_{\mu}^{\prime}}{\partial x^{\prime \nu}}=\frac{\partial x^{\alpha}}{\partial x^{\prime \mu}} \frac{\partial x^{\beta}}{\partial x^{\prime \nu}} \frac{\partial V_{\alpha}}{\partial x^{\beta}}+\frac{\partial^{2} x^{\alpha}}{\partial x^{\prime \nu} \partial x^{\prime \mu}} V_{\alpha}
$$

dari (146), maka menjadi

$$
\begin{aligned}
\frac{\partial V_{\mu}^{\prime}}{\partial x^{\prime \nu}} & =\frac{\partial x^{\alpha}}{\partial x^{\prime \mu}} \frac{\partial x^{\beta}}{\partial x^{\prime \nu}} \frac{\partial V_{\alpha}}{\partial x^{\beta}}+\left(\Gamma_{\nu \mu}^{\prime \lambda} \frac{\partial x^{\alpha}}{\partial x^{\prime \lambda}}-\frac{\partial x^{\kappa}}{\partial x^{\prime \mu}} \frac{\partial x^{\lambda}}{\partial x^{\prime \nu}} \Gamma_{\kappa \lambda}^{\alpha}\right) V_{\alpha} \\
\frac{\partial V_{\mu}^{\prime}}{\partial x^{\prime \nu}}-\Gamma_{\nu \mu}^{\prime \lambda} V_{\lambda}^{\prime} & =\frac{\partial x^{\alpha}}{\partial x^{\prime \mu}} \frac{\partial x^{\beta}}{\partial x^{\prime \nu}}\left(\frac{\partial V_{\alpha}}{\partial x^{\beta}}-\Gamma_{\alpha \beta}^{\lambda} V_{\lambda}\right)
\end{aligned}
$$

disimpulkan

$$
\nabla_{\beta} V_{\alpha}=\frac{\partial V_{\alpha}}{\partial x^{\beta}}-\Gamma_{\alpha \beta}^{\lambda} V_{\lambda}
$$

Sedangkan untuk tensor rank-2, dapat digunakan sifat ke-2 covariant derivative, dimana

$$
\begin{aligned}
\nabla_{\mu} T_{\beta}^{\alpha}=\nabla_{\mu}\left(A^{\alpha} B_{\beta}\right) & =\left(\nabla_{\mu} A^{\alpha}\right) B_{\beta}+A^{\alpha} \nabla_{\mu} B_{\beta}=\left(\frac{\partial A^{\alpha}}{\partial x^{\mu}}+\Gamma_{\mu \lambda}^{\alpha} A^{\lambda}\right) B_{\beta}+A^{\alpha}\left(\frac{\partial B_{\beta}}{\partial x^{\mu}}-\Gamma_{\mu \beta}^{\lambda} B_{\lambda}\right) \\
& =\frac{\partial\left(A^{\alpha} B_{\beta}\right)}{\partial x^{\mu}}+\Gamma_{\mu \lambda}^{\alpha} A^{\lambda} B_{\beta}-\Gamma_{\mu \beta}^{\lambda} A^{\alpha} B_{\lambda}=\frac{\partial T_{\beta}^{\alpha}}{\partial x^{\mu}}+\Gamma_{\mu \lambda}^{\alpha} T_{\beta}^{\lambda}-\Gamma_{\mu \beta}^{\lambda} T_{\lambda}^{\alpha}
\end{aligned}
$$

ini dapat digeneralisir ke rank-n

\section{H Lampiran 8}

Covariant derivative untuk tensor metrik adalah

$$
\nabla_{\alpha} g_{\mu \nu}=g_{\mu \nu, \alpha}-\Gamma_{\alpha \mu}^{\lambda} g_{\lambda \nu}-\Gamma_{\alpha \nu}^{\lambda} g_{\mu \lambda}
$$

menjabarkan simbol christoffel, didapat

$$
\begin{aligned}
\nabla_{\alpha} g_{\mu \nu} & =g_{\mu \nu, \alpha}-\frac{1}{2} g^{\lambda \sigma}\left(g_{\sigma \alpha, \mu}+g_{\sigma \mu, \alpha}-g_{\alpha \mu, \sigma}\right) g_{\lambda \nu}-\frac{1}{2} g^{\lambda \sigma}\left(g_{\sigma \alpha, \nu}+g_{\sigma \nu, \alpha}-g_{\alpha \nu, \sigma}\right) g_{\mu \lambda} \\
& =g_{\mu \nu, \alpha}-\frac{1}{2} \delta_{\nu}^{\sigma}\left(g_{\sigma \alpha, \mu}+g_{\sigma \mu, \alpha}-g_{\alpha \mu, \sigma}\right)-\frac{1}{2} \delta_{\mu}^{\sigma}\left(g_{\sigma \alpha, \nu}+g_{\sigma \nu, \alpha}-g_{\alpha \nu, \sigma}\right) \\
& =g_{\mu \nu, \alpha}-\frac{1}{2} g_{\nu \alpha, \mu}-\frac{1}{2} g_{\nu \mu, \alpha}+\frac{1}{2} g_{\alpha \mu, \nu}-\frac{1}{2} g_{\mu \alpha, \nu}-\frac{1}{2} g_{\mu \nu, \alpha}+\frac{1}{2} g_{\alpha \nu, \mu} \\
& =g_{\mu \nu, \alpha}-\frac{1}{2} g_{\nu \mu, \alpha}-\frac{1}{2} g_{\mu \nu, \alpha}=g_{\mu \nu, \alpha}-g_{\mu \nu, \alpha}=0
\end{aligned}
$$




\section{Lampiran 9}

Geodesik pada ruang datar menggunakan koordinat polar. Telah diketahui bahwa solusi geodesik pada ruang datar adalah garis lurus, namun kita akan memastikannya menggunakan persamaan geodesik yang telah dikonstruksikan sebelumnya dengan koordinat polar. Pada koordinat polar

$$
x^{\mu}=(0, r, \theta, 0) ; \quad g_{\mu \nu}=\left(\begin{array}{cc}
1 & 0 \\
0 & r^{2}
\end{array}\right) ; \quad g^{\mu \nu}=\left(\begin{array}{cc}
1 & 0 \\
0 & \frac{1}{r^{2}}
\end{array}\right)
$$

Maka komponen simbol christoffelnya

$$
\Gamma_{11}^{1}=\Gamma_{12}^{1}=\Gamma_{21}^{1}=0
$$

dan

$$
\Gamma_{22}^{1}=-r
$$

komponen kedua

$$
\Gamma_{11}^{2}=\Gamma_{22}^{2}=0
$$

dan

$$
\Gamma_{12}^{2}=\Gamma_{21}^{2}=-\frac{1}{r}
$$

kita evaluasi geodesik untuk $\mu=1$,

$$
\ddot{x}^{1}+\Gamma_{\alpha \beta}^{1} \dot{x}^{\alpha} \dot{x}^{\beta}=\ddot{x}^{1}+\Gamma_{11}^{1} \dot{x}^{1} \dot{x}^{1}+\ddot{x}^{1}+2 \Gamma_{12}^{1} \dot{x}^{1} \dot{x}^{2}+\ddot{x}^{1}+\Gamma_{22}^{1} \dot{x}^{2} \dot{x}^{2}=\ddot{x}^{1}+\Gamma_{22}^{1}\left(\dot{x}^{2}\right)^{2}
$$

didapat

$$
\frac{d^{2} r}{d \lambda^{2}}-r\left(\frac{d \theta}{d \lambda}\right)^{2}=0
$$

sedangkan $\mu=2$

$$
\ddot{x}^{2}+2 \Gamma_{12}^{2} \dot{x}^{1} \dot{x}^{2}=0
$$

didapat

$$
\frac{d^{2} \theta}{d \lambda^{2}}+\frac{2}{r}\left(\frac{d r}{d \lambda} \frac{d \theta}{d \lambda}\right)=\frac{1}{\dot{\theta}} \frac{d \dot{\theta}}{d \lambda}+\frac{2}{r} \frac{d r}{d \lambda}=0
$$

dievaluasi dahulu persaman diatas

$$
\frac{d \ln (\dot{\theta})}{d \lambda}+2 \frac{d \ln (r)}{d \lambda}=0 \rightarrow \ln (\dot{\theta})+\ln \left(r^{2}\right)=C \rightarrow \dot{\theta} r^{2}=e^{c}=k
$$

dipilih affine paramater $\lambda$ sebagai $s$, sehingga $d \lambda=d s=\sqrt{g_{\mu \nu} d x^{\mu} d x^{\nu}}$, maka

$$
\begin{aligned}
d s^{2} & =d r^{2}+r^{2} d \theta^{2} \quad \times \frac{1}{d \lambda^{2}} \\
1 & =\left(\frac{d r}{d s}\right)^{2}+\left(r \frac{d \theta}{d s}\right)^{2}=\left(\frac{d r}{d s}\right)^{2}+\frac{k^{2}}{r^{2}} \rightarrow \frac{d r}{d s}=\sqrt{1-\frac{k^{2}}{r^{2}}}= \pm \frac{1}{r}\left(r^{2}-k^{2}\right)^{1 / 2}
\end{aligned}
$$

lalu

$$
\frac{d r}{d \theta}=\frac{d r / d s}{d \theta / d s}= \pm \frac{r}{k}\left(r^{2}-k^{2}\right)^{1 / 2} \rightarrow \int \frac{k}{r}\left(r^{2}-k^{2}\right)^{-1 / 2} d r= \pm \int d \theta
$$

memiliki solusi

$$
\cos ^{-1}\left(\frac{k}{r}\right)=\theta-\theta_{0}
$$

yang dimana merupakan persamaan garis lurus pada koordinat polar

$$
r=\frac{k}{\cos \left(\theta-\theta_{0}\right)}
$$




\section{J Lampiran 10}

Tensor kelengkungan Riemann dengan semua indeks kovarian ditulis

$$
\begin{aligned}
R_{\rho \sigma \mu \nu} & =g_{\alpha \rho} R_{\sigma \mu \nu}^{\alpha}=g_{\alpha \rho}\left(\partial_{\mu} \Gamma_{\nu \sigma}^{\alpha}-\partial_{\nu} \Gamma_{\mu \sigma}^{\alpha}+\Gamma_{\mu \lambda}^{\alpha} \Gamma_{\nu \sigma}^{\lambda}-\Gamma_{\nu \lambda}^{\alpha} \Gamma_{\mu \sigma}^{\lambda}\right) \\
& =\left[\partial_{\mu}\left(g_{\alpha \rho} \Gamma_{\nu \sigma}^{\alpha}\right)-\partial_{\nu}\left(g_{\alpha \rho} \Gamma_{\mu \sigma}^{\alpha}\right)\right]-\left(\Gamma_{\nu \sigma}^{\alpha} \partial_{\mu} g_{\alpha \rho}-\Gamma_{\mu \sigma}^{\alpha} \partial_{\nu} g_{\alpha \rho}\right)+g_{\alpha \rho}\left(\Gamma_{\mu \lambda}^{\alpha} \Gamma_{\nu \sigma}^{\lambda}-\Gamma_{\nu \lambda}^{\alpha} \Gamma_{\mu \sigma}^{\lambda}\right)
\end{aligned}
$$

dimana

$$
\begin{aligned}
g_{\alpha \rho} \Gamma_{\nu \sigma}^{\alpha} & =\frac{1}{2} g_{\alpha \rho} g^{\alpha \beta}\left(g_{\beta \nu, \sigma}+g_{\beta \sigma, \nu}-g_{\nu \sigma, \beta}\right)=\frac{1}{2} \delta_{\rho}^{\beta}\left(g_{\beta \nu, \sigma}+g_{\beta \sigma, \nu}-g_{\nu \sigma, \beta}\right)=\frac{1}{2}\left(g_{\rho \nu, \sigma}+g_{\rho \sigma, \nu}-g_{\nu \sigma, \rho}\right) \\
\partial_{\mu}\left(g_{\alpha \rho} \Gamma_{\nu \sigma}^{\alpha}\right) & =\frac{1}{2}\left(\partial_{\mu} \partial_{\sigma} g_{\rho \nu}+\partial_{\mu} \partial_{\nu} g_{\rho \sigma}-\partial_{\mu} \partial_{\rho} g_{\nu \sigma}\right)
\end{aligned}
$$

dan suku kedua hanya pertukaran indeks, didapat

$$
\partial_{\nu}\left(g_{\alpha \rho} \Gamma_{\mu \sigma}^{\alpha}\right)=\frac{1}{2}\left(\partial_{\nu} \partial_{\sigma} g_{\rho \mu}+\partial_{\nu} \partial_{\mu} g_{\rho \sigma}-\partial_{\nu} \partial_{\rho} g_{\mu \sigma}\right)
$$

didapat

$$
\left[\partial_{\mu}\left(g_{\alpha \rho} \Gamma_{\nu \sigma}^{\alpha}\right)-\partial_{\nu}\left(g_{\alpha \rho} \Gamma_{\mu \sigma}^{\alpha}\right)\right]=\partial_{\mu} \partial_{\sigma} g_{\rho \nu}-\partial_{\mu} \partial_{\rho} g_{\nu \sigma}-\partial_{\nu} \partial_{\sigma} g_{\rho \mu}+\partial_{\nu} \partial_{\rho} g_{\mu \sigma}
$$

dimana suku tengah masing-masing saling menghilangkan. Suku ketiga dan suku keempat persamaan pertama saling menghilangkan, sehingga disimpulkan tensor kelengkungan Riemann dengan semua indeks kovarian adalah

$$
R_{\rho \sigma \mu \nu}=\partial_{\mu} \partial_{\sigma} g_{\rho \nu}-\partial_{\mu} \partial_{\rho} g_{\nu \sigma}-\partial_{\nu} \partial_{\sigma} g_{\rho \mu}+\partial_{\nu} \partial_{\rho} g_{\mu \sigma}+\Gamma_{\mu \lambda}^{\alpha} \Gamma_{\nu \sigma}^{\lambda}-\Gamma_{\nu \lambda}^{\alpha} \Gamma_{\mu \sigma}^{\lambda}
$$

